\title{
Epigenetic modification of Nrf2 in 5-fluorouracil-resistant colon cancer cells: involvement of TET-dependent DNA demethylation
}

\author{
KA Kang ${ }^{1}$, MJ Piao ${ }^{1}$, KC Kim ${ }^{1}$, HK Kang ${ }^{1}$, WY Chang ${ }^{1}$, IC Park ${ }^{2}$, YS Keum ${ }^{3}$, YJ Surh ${ }^{4}$ and JW Hyun ${ }^{\star, 1}$
}

5-Fluorouracil (5-FU) is a widely used anticancer drug for the treatment of colorectal cancer (CRC). However, resistance to 5-FU often prevents the success of chemotherapy. Nuclear factor-erythroid 2-related factor 2 (Nrf2) is a transcriptional regulator and a possible target to overcome 5-FU resistance. The present study examined epigenetic changes associated with Nrf2 induction in a human CRC cell line (SNUC5) resistant to 5-FU (SNUC5/5-FUR). Nrf2 expression, nuclear translocation, and binding to promoter were higher in SNUC5/5-FUR cells than in SNUC5 cells. The activated Nrf2 in SNUC5/5-FUR cells led to an increase in the protein expression and activity of heme oxygenase-1 (HO-1), an Nrf2-regulated gene. SNUC5/5-FUR cells produced a larger amount of reactive oxygen species (ROS) than SNUC5 cells. The siRNA- or shRNA-mediated knockdown of Nrf2 or H0-1 significantly suppressed cancer cell viability and tumor growth in vitro and in vivo, resulting in enhanced 5-FU sensitivity. Methylationspecific (MS) or real-time quantitative MS-PCR data showed hypomethylation of the Nrf2 promoter CpG islands in SNUC5/5-FUR cells compared with SNUC5 cells. Expression of the DNA demethylase ten-eleven translocation (TET) was upregulated in SNUC5/ 5-FUR cells. ROS generated by 5-FU upregulated TET1 expression and function, whereas antioxidant had the opposite effect. These results suggested that the mechanism underlying the acquisition of 5-FU resistance in CRC involves the upregulation of Nrf2 and HO-1 expression via epigenetic modifications of DNA demethylation.

Cell Death and Disease (2014) 5, e1183; doi:10.1038/cddis.2014.149; published online 17 April 2014

Subject Category: Cancer

The fluoropyrimidine 5-fluorouracil (5-FU) is an anticancer drug that is widely used in the treatment of solid tumors, including colorectal cancers (CRCs). ${ }^{1}$ The mechanism of 5 -FU action has been associated with the inhibition of thymidylate synthase and the incorporation of 5-FU into RNA and DNA. ${ }^{1}$ Although a better understanding of the mechanism of 5-FU action has been gained in recent years, the development of drug-resistant phenotypes remains a significant limitation to its clinical use. Therefore, new treatment strategies aimed at overcoming 5-FU resistance are urgently needed.

Heme oxygenase-1 (HO-1) plays an important role in the maintenance of cellular redox homeostasis and hence prevents transformation of normal cells to precancer cancer cells by counteracting reactive oxygen species (ROS)-mediated carcinogenesis. ${ }^{2}$ However, abnormally increased levels of $\mathrm{HO}-1$ have been found in various cancers including CRCs, describing it as a precancer molecule because of its antiapoptotic and proangiogenic effects. $^{3-5}$ Furthermore, overexpression of $\mathrm{HO}-1$ provides cancer cells with active survival properties that can result in a poor clinical outcome. ${ }^{6,7} \mathrm{HO}-1$ expression in cancer cells is increased by anticancer treatment, such as chemotherapy, radiotherapy, and photodynamic therapy. ${ }^{8}$ Especially, $\mathrm{HO}-1$ has been implicated in the resistance of cancer cells to chemotherapeutic agents including 5-FU. ${ }^{9-11}$

The nuclear factor-erythroid 2-related factor 2 (Nrf2) is a redox-sensitive transcription factor that regulates the expression of phase II antioxidant genes including $\mathrm{HO}-1$ and confers cytoprotection against oxidative stress. ${ }^{12,13}$ In unstressed cells, Nrf2 is sequestered by kelch-like $\mathrm{ECH}$-associated protein 1 (Keap1) that promotes its rapid proteasomemediated degradation. ${ }^{14}$ However, in response to oxidative stress, Nrf2 is stabilized by dissociating from Keap1, and binds to cis-elements called antioxidant response elements (AREs). ${ }^{15}$ Recent studies showed that Nrf2 expression is upregulated in various human cancers, suggesting its possible involvement in carcinogenesis during several stages of cancer, such as initiation, progression, and resistance to chemotherapy. ${ }^{16,17}$ Recently, it has been reviewed that Nrf2 and its principal target protein $\mathrm{HO}-1$ may have oncogenic potential, suggesting proliferation of cancer cells, resistance to anticancer treatment, and metastasis or angiogenesis in cancer progression. ${ }^{8}$ Therefore, Nrf2 and $\mathrm{HO}-1$ might represent a key system involved in 5-FU resistance.

\footnotetext{
${ }^{1}$ School of Medicine, Jeju National University, Jeju, Korea; ${ }^{2}$ Division of Radiation Cancer Research, Korea Institute of Radiological and Medical Sciences, Seoul, Korea; ${ }^{3}$ Department of Biochemistry, College of Pharmacy, Dongguk University, Goyang, Korea and ${ }^{4}$ Tumor Microenvironment Global Core Research Center and Cancer Research Institute, Seoul National University, Seoul, Korea

*Corresponding author: JW Hyun, School of Medicine, Jeju National University, Jeju 690-756, Korea. Tel: +82 64 7543838; Fax: +82 64 7264152; E-mail: jinwonh@jejunu.ac.kr

Keywords: colon cancer cells; 5-fluorouracil resistance; epigenetic modification; DNA demethylase; Nrf2; oxidative stress

Abbreviations: 5-FU, 5-fluorouracil; CRC, colorectal cancer; Nrf2, nuclear factor-erythroid 2-related factor 2; HO-1, heme oxygenase-1; ROS, reactive oxygen species; TET, ten-eleven translocation; Keap1, kelch-like ECH-associated protein 1; ARE, antioxidant response element; DNMT, DNA methyltransferase; 5-mC, 5-methylcytosine; 5-hmC, 5-hydroxymethylcytosine; 5-fC, 5-formylcytosine; 5-caC, 5-carboxylcytosine

Received 17.12.13; revised 07.3.14; accepted 10.3.14; Edited by A Stephanou
} 
DNA methylation is an epigenetic event involved in the control of gene expression that is known to play an important role in cancer and chemotherapy drug resistance. For example, changes in the DNA methylation machinery are associated with resistance to docetaxel in breast cancer cells. ${ }^{18}$ Aberrant upregulation of achaete scute-like 2, a DNA transcription activator, by promoter demethylation promotes the growth and 5-FU resistance of gastric cancer cells. ${ }^{19}$ DNA methylation is catalyzed by three DNA methyltransferases (DNMTs): DNMT1, DNMT3A, and DNMT3B, all of which add a methyl group to the $\mathrm{C} 5$ position of the cytosine ring of the DNA leading to 5-methylcytosine (5-mC). DNMT1 expression is upregulated in tamoxifen-resistant breast cancer cells and it leads to aberrant methylation of the phosphatase and tensin homolog (PTEN) gene promoter, resulting in low expression of PTEN. ${ }^{20}$ The adriamycin-resistant breast cancer cells exhibited the multidrug-resistant phenotype accompanied by global DNA hypermethylation, overexpression of DNMT genes, and increased DNMT activity. ${ }^{21}$ These reports suggest that DNA hypermethylation by DNMTs is at least partly responsible for development of the anticancer drug-resistant phenotype in cancer.

This methylation process can be reversed by DNA demethylases, ten-eleven translocation enzymes (TETs): TET1, TET2, and TET3. ${ }^{22}$ These enzymes can convert 5 -mC to 5-hydroxymethylcytosine (5-hmC), 5-formylcytosine (5-fC), and 5-carboxylcytosine (5-caC), finally leading to cytosine. $^{22,23}$ These modified bases may not only serve as intermediates in the DNA demethylation process, but may also increase the diversity of the epigenetic states of genomic DNA. In the present study, we investigated the mechanisms underlying 5-FU resistance, focusing on the involvement of Nrf2 and alterations of DNA methylation in CRC.

\section{Results}

Sensitivity of SNUC5 and SNUC5/5-FUR cells to 5-FU. The cytotoxic effect of 5-FU in the SNUC5 cell line and its 5-FU-resistant variant, SNUC5/5-FUR, was compared. The concentration of $5-\mathrm{FU}$ that yielded $50 \%$ growth inhibition $\left(\mathrm{IC}_{50}\right)$ was $9 \mu \mathrm{M}$ in SNUC5 cells and $2264 \mu \mathrm{M}$ in SNUC5/5-FUR cells, in which resistance was induced by continuous culture in $140 \mu \mathrm{M} 5$-FU (Figure 1a). These results were confirmed by a colony formation assay; the colony numbers in both cell lines were decreased by $\mathrm{IC}_{50}$ concentration of 5-FU compared with the untreated group (Figure 1b). 5-FU treatment induced apoptosis in both cell lines, as shown by annexin $\mathrm{V}$-propidium iodide $(\mathrm{PI})$ staining and TdT-mediated dUTP nick end labeling (TUNEL) staining. The annexin $\mathrm{V}^{+} \mathrm{PI}^{-}$(apoptotic) population showed 29\% in SNUC5 and 31\% in SNUC5/5-FUR cells (Figure 1c). TUNEL staining data were consistent with annexin V-PI data (Figure 1d).

Induction of HO-1 and Nrf2 in SNUC5 and SNUC5/5-FUR cells. HO-1 expression and activity were higher in SNUC5/ 5 -FUR cells than in SNUC5 cells (Figures $2 a$ and b). Nuclear $\mathrm{Nrf2}$, a transcription factor for $\mathrm{HO}-1$, and active Nrf2 (phospho Nrf2) expression were higher in SNUC5/5-FUR cells than in SNUC5 cells, and Nrf2 and phospho Nrf2 expression in cytosol were lower in SNUC5/5-FUR cells than in SNUC5 cells (Figure 2c). The enhanced translocation of Nrf2 protein from the cytosol to the nucleus (Figure 2d) and its binding to the ARE sequence in the $\mathrm{HO}-1$ promoter (Figure 2e) were shown in SNUC5/5-FUR cells.

Intracellular ROS levels in SNUC5 and SNUC5/5-FUR cells. Flow cytometry data showed that ROS levels were higher in SNUC5/5-FUR cells (fluorescence intensity (FI) 342) than in SNUC5 cells ( $\mathrm{FI} 132$ ), and $\mathrm{H}_{2} \mathrm{O}_{2}$ treatment in SNUC5 cells (FI 640) was used as positive control (Figure $3 a$ ). These results were confirmed by confocal microscopic data; green FI generated by ROS was enhanced in SNUC5/5-FUR cells as compared with SNUC5 cells (Figure 3b). These results suggested that SNUC5/5-FUR cells were exposed to more oxidative stress condition than SNUC5 cells.

Sensitivity of 5-FU on Nrf2 and HO-1 knockdown in vitro and in vivo. The putative roles of $\mathrm{Nrf} 2$ and $\mathrm{HO}-1$ on the sensitivity of 5-FU in SNUC5/5-FUR cells were investigated by siRNA- or shRNA-mediated silencing in vitro and in vivo. The siNrf2- or siHO-1-transfected cells significantly lowered cell viability or colony formation numbers than siContransfected cells (Figures 4a and b). 5-FU (140 $\mu \mathrm{M})$ treatment in siNrf2- or siHO-1-transfected cells significantly lowered cell viability or colony formation numbers than 5-FU treatment in siCon-transfected cells or 5-FU-untreated siNrf2- and siHO-1-transfected cells (Figures $4 \mathrm{a}$ and b). In addition, the mice implanted with shNrf2- or shHO-1-transfected SNUC5/ 5-FUR cells had reduced tumor volume, size, weight, and apoptotic cells than mice implanted with shCon-transfected cells (Figures $4 \mathrm{c}-\mathrm{f}) .5-\mathrm{FU}$ treatment $(20 \mathrm{mg} / \mathrm{kg} /$ day) in mice implanted with shNrf2- or shHO-1-transfected cells reduced tumor volume, size, weight, and apoptotic cells than the 5-FU treatment in mice implanted with shCon-transfected cells or phosphate-buffered saline (PBS) treatment in mice implanted with shNrf2- or shHO-1-transfected cells (Figures 4c-f).

DNA methylation levels in SNUC5 and SNUC5/5-FUR cells. Methylation of the Nrf2 promoter was assessed using methylation-specific PCR (MS-PCR) and quantitative MS-PCR. Specific CpG sites in the promoter region of the Nrf2 gene were methylated in SNUC5 cells, but less methylated in SNUC5/5-FUR cells (Figure 5a). These results were confirmed by quantitative MS-PCR; the levels of methylation of the Nrf2 gene in SNUC5 and SNUC5/5-FUR cells were $35 \%$ and $5 \%$, respectively (Figure $5 b$ ).

DNA methylation-related proteins DNMTs and TETs in SNUC5 and SNUC5/5-FUR cells. The expression of epigenetic modification-related proteins in terms of DNA methylation was investigated by assessing the levels of DNMTs DNMT1, DNMT3A, and DNMT3B, and DNA demethylases TET1, TET2, and TET3. DNMT expression did not show significant difference between SNUC5 and SNUC5/5-FUR cells, whereas TET expression was higher in SNUC5/5-FUR cells than in SNUC5 cells (Figure 6a). Also, TET1 expression was confirmed by confocal imaging (Figure 6b). TET1 binding to the Nrf2 promoter was 


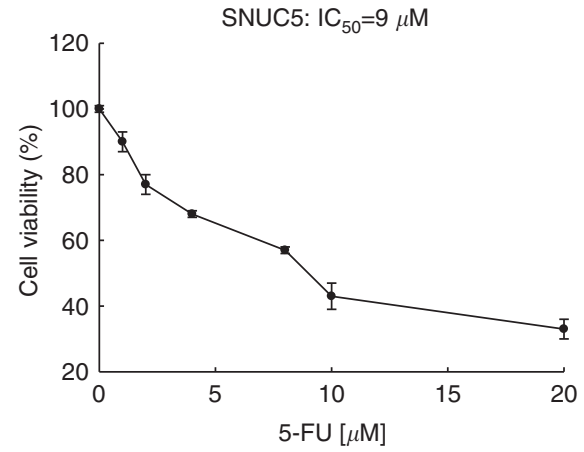

SNUC5/5-FUR: IC ${ }_{50}=2264 \mu \mathrm{M}$

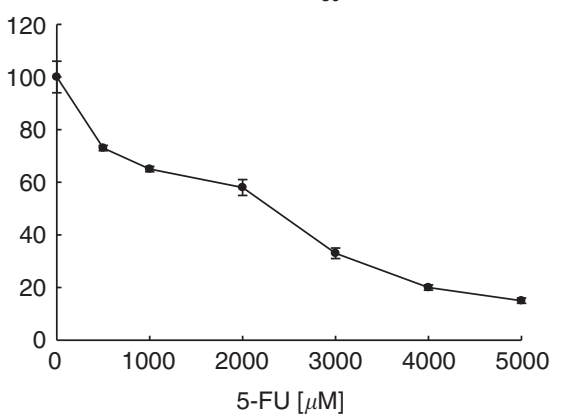

b

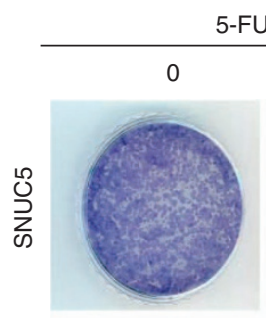

0
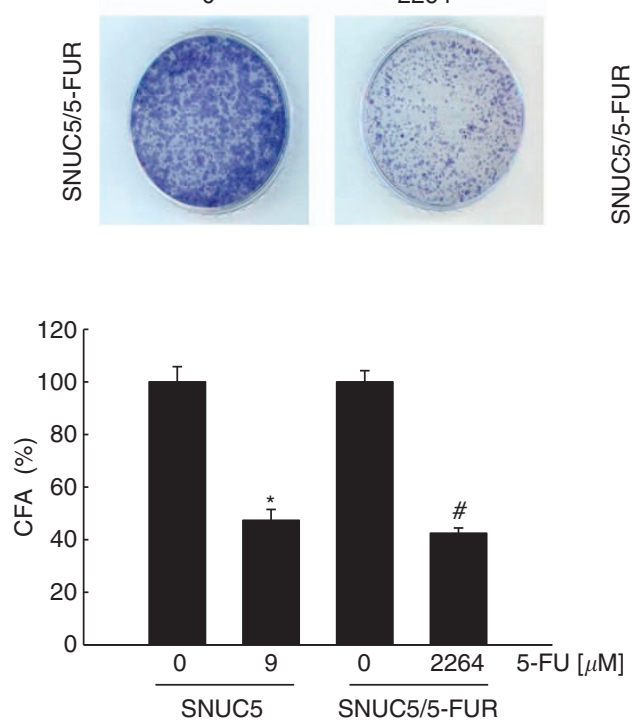

C
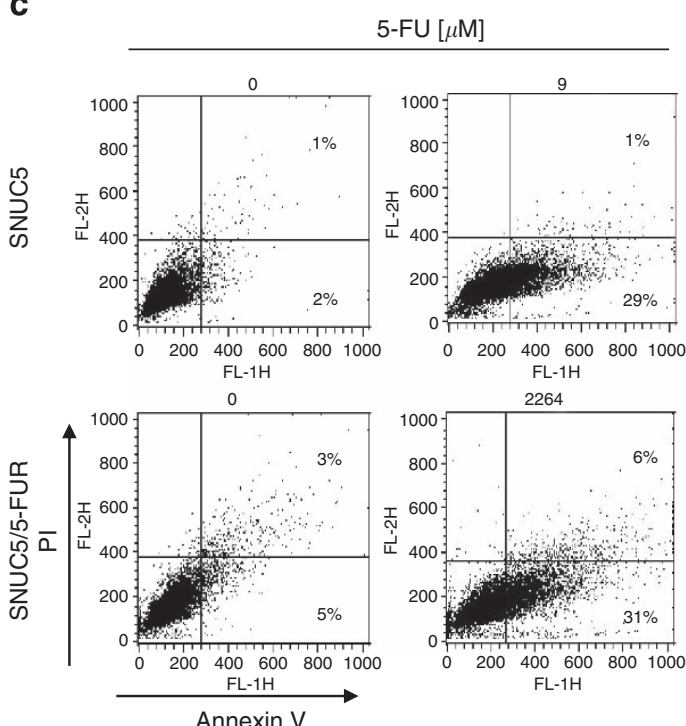

d

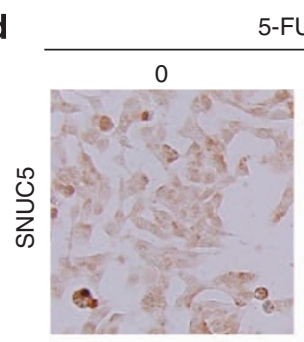

0

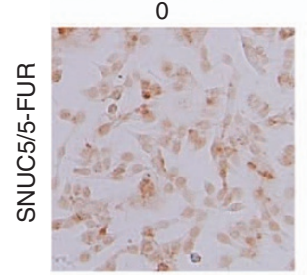

$5-\mathrm{FU}[\mu \mathrm{M}]$

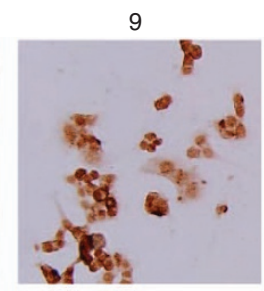

2264

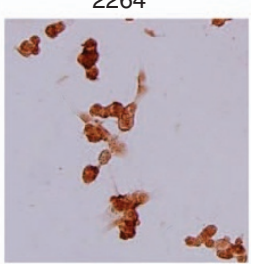

Figure 1 Sensitivity of SNUC5 and SNUC5/5-FUR cells to 5-FU. Cells were treated with 5-FU. (a) After 2 days, cell viability was assessed using the MTT assay. (b) After 10 days, the colony forming ability (CFA) was assessed by using a colony staining kit. *Significantly different from untreated SNUC5 cells $(P<0.05)$ and " ${ }^{*}$ significantly different from untreated SNUC5/5-FUR cells $(P<0.05)$. Apoptosis was detected by $(\mathbf{c})$ annexin V-PI staining and (d) TUNEL staining

significantly increased in SNUC5/5-FUR cells, as assessed using a chromatin immunoprecipitation (ChIP) assay, whereas DNMT1 did not show significant difference to Nrf2 promoter binding in both cell lines (Figure 6c). Furthermore, knockdown of TET1 decreased expression of Nrf2 mRNA and protein in SNUC5/5-FUR cells, whereas knockdown of DNMT1 did not affect it (Figures 6d and e). Also, knockdown of TET1 resulted in a reduction of HO-1 protein expression and activity, but knockdown of DNMT1 did not change it (Figures $6 e$ and f). These results suggest that TET1 can positively regulate Nrf2 activation in SNUC5/5-FUR cells. 


KA Kang et al

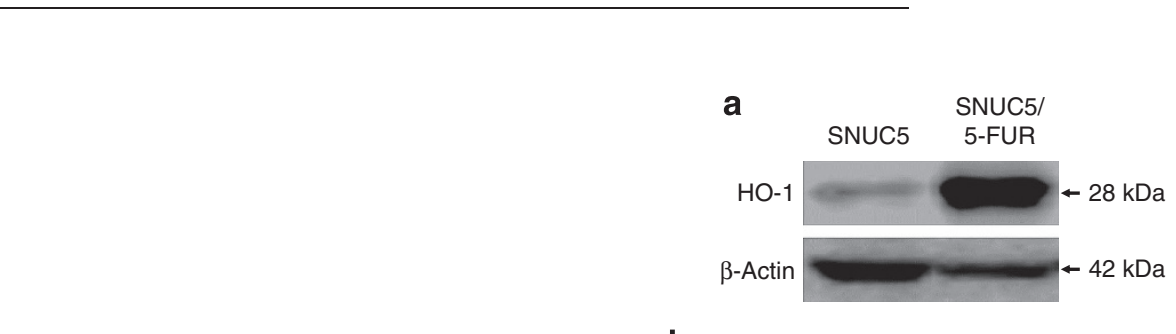

b

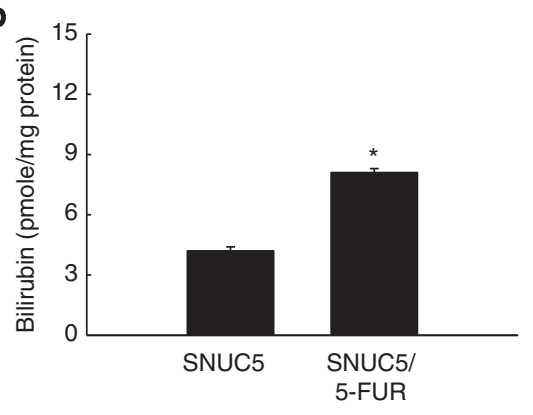

c
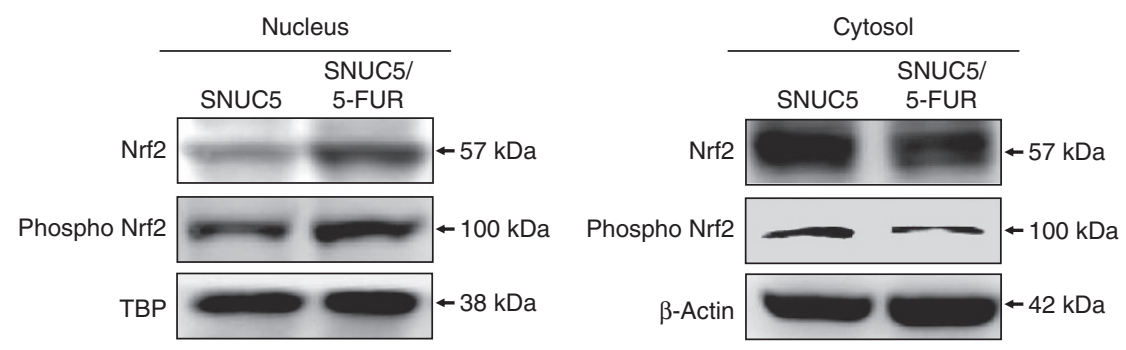

d

Nrf2

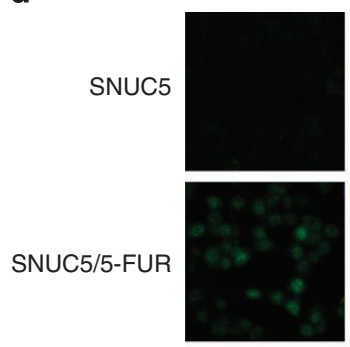

Phospho Nrf2

SNUC5

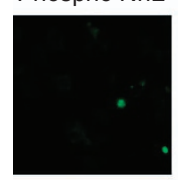

SNUC5/5-FUR

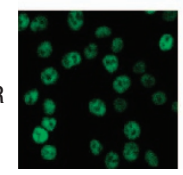

DAPI
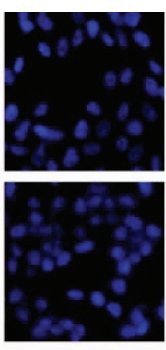

DAPI
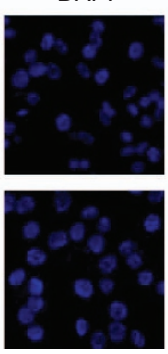

Merge

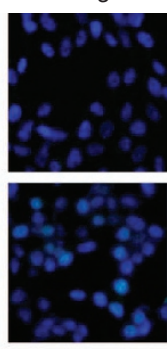

Merge

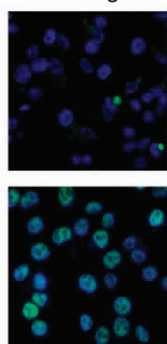

e
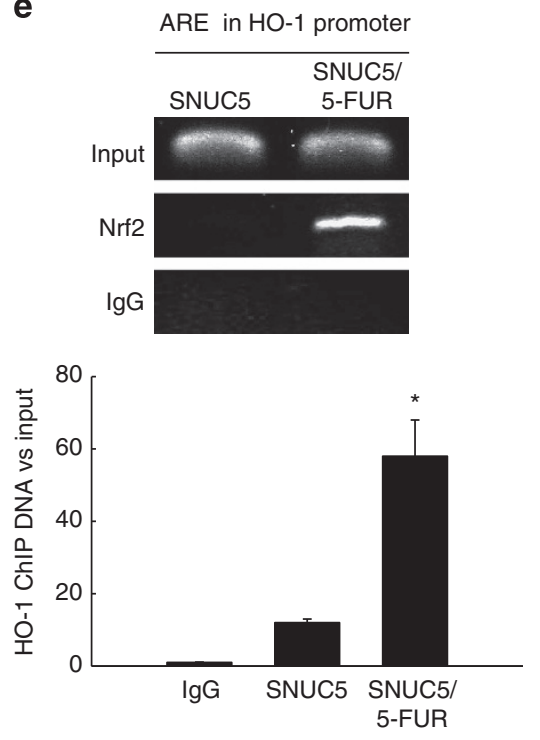

Figure 2 Expression of HO-1 and Nrf2 in SNUC5 and SNUC5/5-FUR cells. (a) HO-1 expression and (b) activity as well as (c) Nrf2 expression were determined. The $\beta$-actin antibody was used as loading control for total or cytosolic protein and TBP antibody for nuclear protein. *Significantly different from SNUC5 cells $(P<0.05)$. (d) Confocal images show Nrf2 and phospho Nrf2 (green) expression. DAPI staining indicates nuclei (blue). The merged image indicates the nuclear location of the Nrf2 protein. (e) ChIP analysis was assessed by using an anti-Nrf2 antibody and primers to amplify the HO-1 promoter region and quantified. Input represents amplification of total DNA from whole-cell lysates. IgG was used as negative control

TET activity in SNUC5 and SNUC5/5-FUR cells. TET activity was assessed by measuring the levels of $5-\mathrm{mC}$, $5-\mathrm{hmC}$, and $5-\mathrm{fC}$. The level of 5-mC was lower in SNUC55FUR cells than in SNUC5 cells, whereas levels of $5-\mathrm{hmC}$ and 5 -fC were higher in SNUC5-5FUR cells than in SNUC5 cells, as shown by dot blot analysis (Figure 7a), confocal imaging (Figure 7b), flow cytometry (Figure 7c), and ELISA (Figure 7d).

Effects of 5-FU on Nrf2, ROS, and TET. 5-FU treatment increased levels of nuclear Nrf2 and active Nrf2 (phospho Nrf2) in SNUC5 cells (Figure 8a). Methylation of the Nrf2 
a
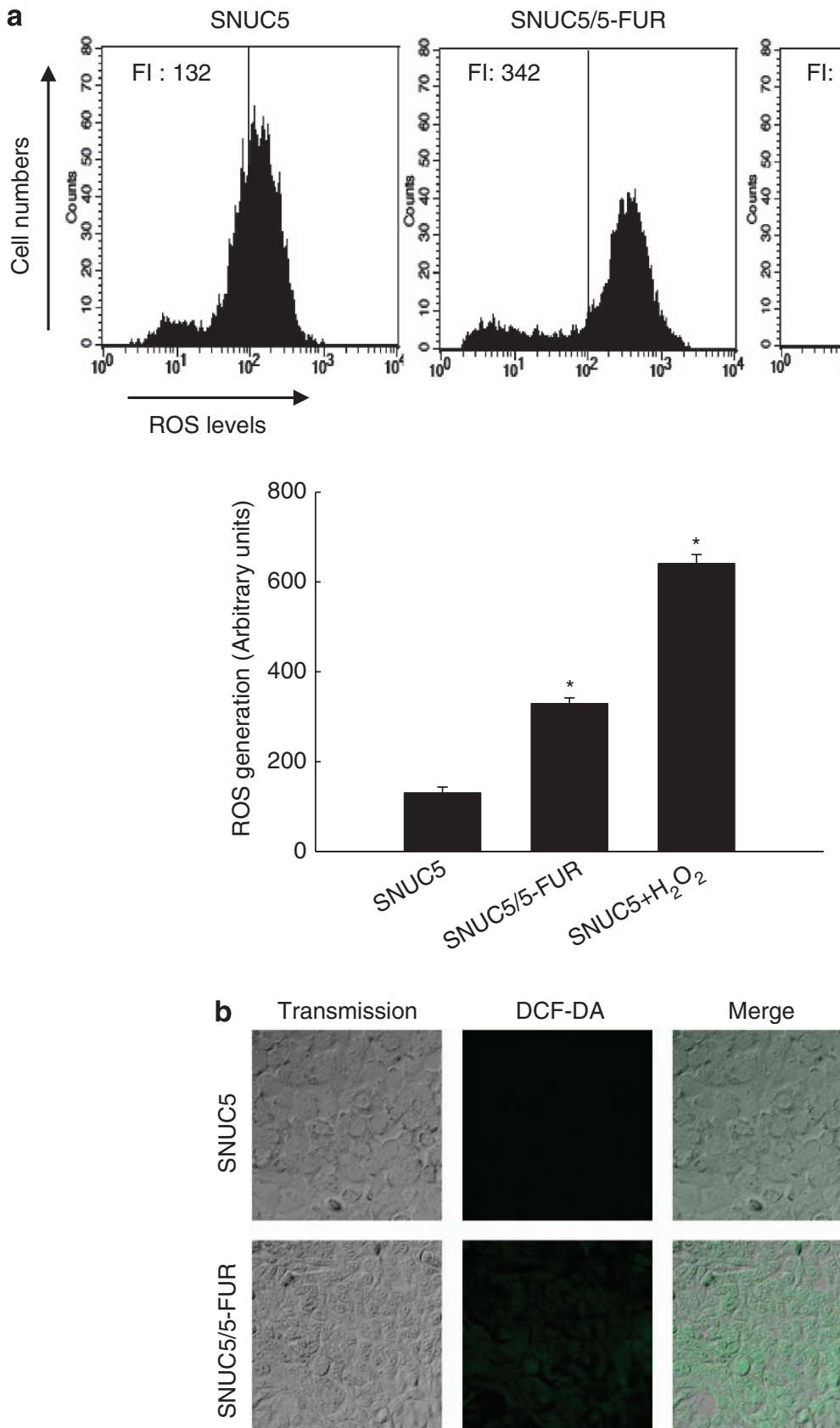

SNUC5/5-FUR
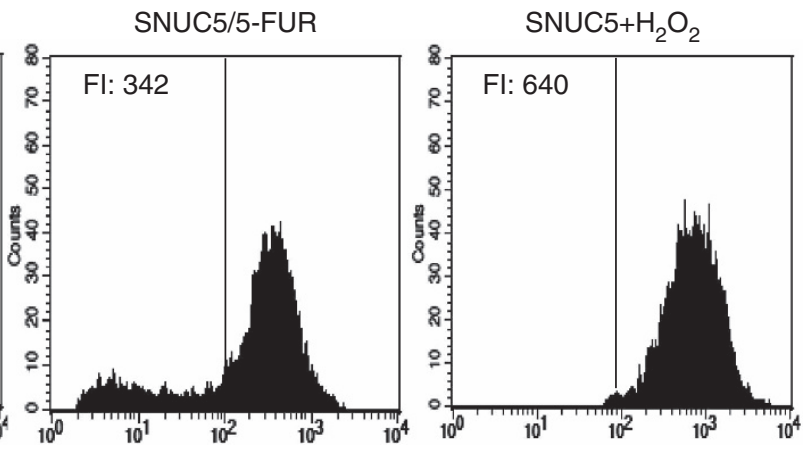

Figure 3 Intracellular ROS levels in SNUC5 and SNUC5/5-FUR cells. ROS inducer $\mathrm{H}_{2} \mathrm{O}_{2}(1000 \mu \mathrm{M})$ treatment in SNUC5 cells was used as positive control. ROS were detected by (a) flow cytometry and (b) confocal imaging after staining of DCF-DA. Fl indicates the fluorescence intensity of DCF. *Significantly different from SNUC5 cells $(P<0.05)$

promoter was decreased in 5-FU-treated SNUC5 cells (Figure $8 b$ ). These results were confirmed by real-time QMSP; the methylation levels of the Nrf2 promoter in control and 5-FU treatment in SNUC5 cells were $44 \%$ and $29 \%$, respectively (Figure 8c). Furthermore, 5-FU treatment significantly increased TET1 expression (Figure 8d), and TET activity in SNUC5 cells (Figure 8e). Moreover, we investigated the effect of 5-FU on ROS and TET1 in SNUC5 cells. 5-FU promoted the production of ROS in SNUC5 cells, whereas treatment with an antioxidant $N$-acetylcystein (NAC) had the opposite effect (Figure 8f). 5-FU increased TET1 expression (Figure $8 \mathrm{~g}$ ) and TET-catalyzed processes (Figures $8 \mathrm{~h}$ and i), but NAC treatment downregulated it, suggesting that the effect of 5-FU on TET expression and function is mediated by its induction of ROS.

\section{Discussion}

5-FU remains the standard therapy for the treatment of patients with CRCs, despite the fact it was developed more than 50 years ago. However, most CRC patients develop resistance to $5-\mathrm{FU} .^{1,24}$ Therefore, elucidating the molecular 
a

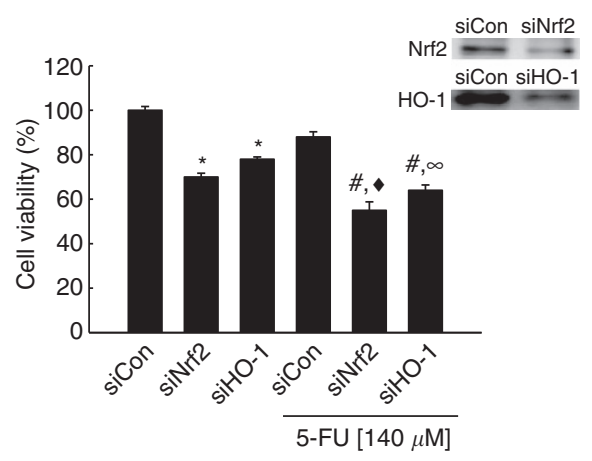

b
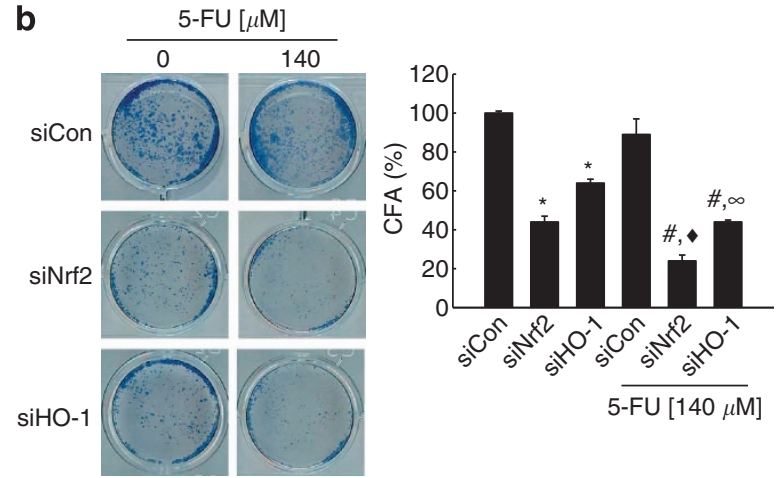

C
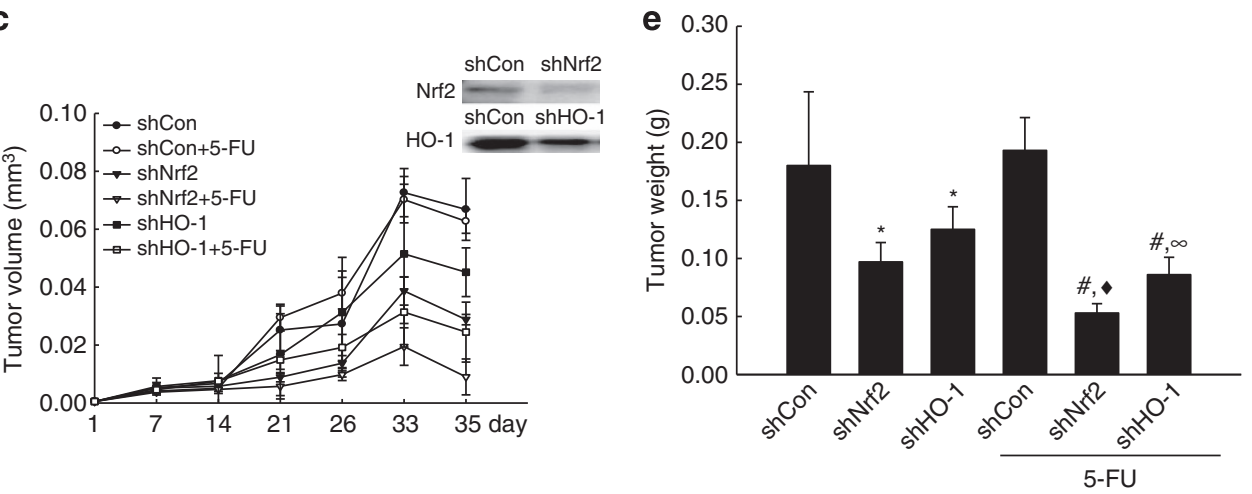

d
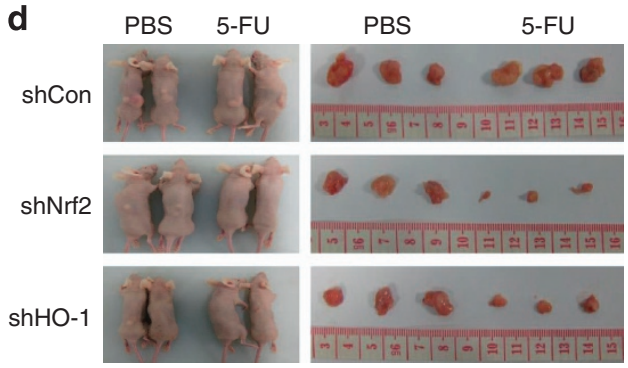

$\mathbf{f}$

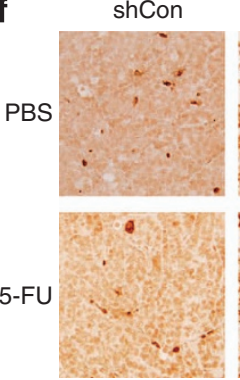

shNrf2

shHO-1
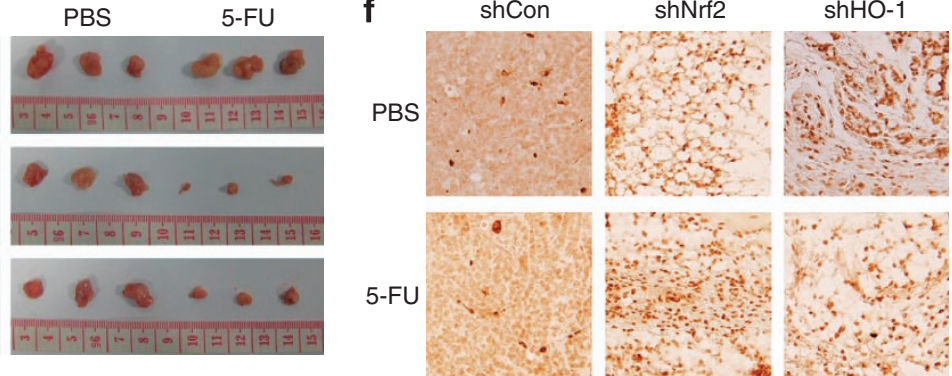

Figure 4 Nrf2 and HO-1 knockdown sensitizes SNUC5/5-FUR cells to 5-FU in vitro and in vivo. SNUC5/5-FUR cells were transfected with siCon, siNrf2, or siHO-1 and incubated for $24 \mathrm{~h}$. (a) Cells were then cultured in the absence or presence of $5-\mathrm{FU}(140 \mu \mathrm{M})$ for $48 \mathrm{~h}$. Cell viability was determined using the MTT assay. (b) For colony forming assay, cells were cultured in the absence or presence of 5-FU $(140 \mu \mathrm{M})$ for 10 days. Colonies with more than 50 cells were counted. *Significantly different from siContransfected cells in the absence of 5-FU $(P<0.05)$, " significantly different from siCon-transfected cells in the presence of 5 -FU $(P<0.05)$, "significantly different from siNrf2transfected cells in the absence of 5-FU $(P<0.05)$, and ${ }^{\infty}$ significantly different from siHO-1-transfected cells in the absence of 5 -FU $(P<0.05)$. An in vivo study was performed using a tumor xenograft mouse model. SNUC5/5-FUR cells were transfected with shCon, shNrf2, or shHO-1 RNA, and then implanted subcutaneously into the backs of nude mice. After 14 days, vehicle (PBS; $n=6)$ or $5-\mathrm{FU}(20 \mathrm{mg} / \mathrm{kg} / \mathrm{day} ; n=6)$ were directly injected into the tumor every 2 days (9 times). Mice were killed and tumors were collected at 35 days after tumor cell injection. (c) The volume, (d) size, and (e) weight of tumors were measured. *Significantly different from vehicle-treated mice that received shCon-transfected cells $(P<0.05)$, " significantly different from 5 -FU-treated mice that received shCon-transfected cells $(P<0.05)$, "significantly different from vehicle-treated mice that received shNif2-transfected cells $(P<0.05)$, and ${ }^{\infty}$ significantly different from vehicle-treated mice that received shHO-1-transfected cells $(P<0.05)$. (f) The induction of apoptosis by 5 -FU was assessed by TUNEL. The representative images are shown 

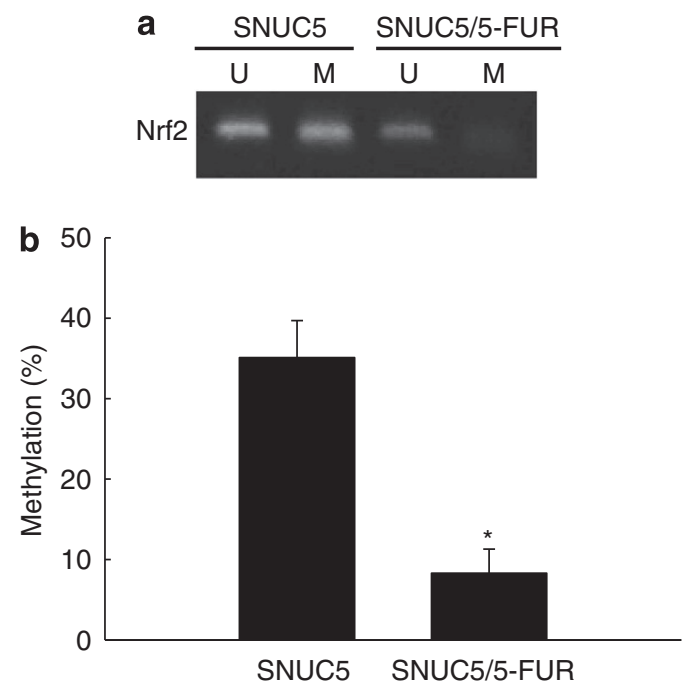

Figure 5 Methylation status of Nrf2 promoter in SNUC5 and SNUC5/5-FUR cells. (a) MS-PCR analysis of the Nrf2 promoter was performed on genomic DNA isolated from SNUC5 and SNUC5/5-FUR cells. Methylation was detected by the amplification of a product using methylation-specific primers. Unmethylation was detected by the amplification of a product using unmethylation-specific primers. M, methylated DNA; U, unmethylated DNA. (b) Real-time QMSP analysis of Nrf2 in SNUC5 and SNUC5/5-FUR cells was assessed. Bars represent the methylation percentage of the $\mathrm{CpG}$ islands. "Significantly different from the SNUC5 cells $(P<0.05)$

mechanisms underlying 5-FU resistance is important for the development of molecular targeted strategies to overcome drug resistance. ${ }^{1}$ Increasing evidence supports the notion that epigenetic alterations play a major role in drug resistance in various cancers, including CRCs. ${ }^{25}$ This suggests that epigenetic agents can be used to overcome CRC drug resistance and increase the efficacy of conventional chemotherapeutic agents in the clinic.

In the present study, we showed that expression of Nrf2 and the Nrf2-related gene HO-1 was upregulated in a 5-FUresistant CRC cell line (SNUC5/5-FUR) compared with the parental cell line (SNUC5). Although the protective role of the Nrf2-antioxidant system against carcinogenesis and chemicals has been well documented in normal cells, its prolonged activation in cancer cells might increase resistance to anticancer drugs. Nrf2 controls a battery of genes including HO-1 that protect cells from chemical and oxidative stresses, and are activated in CRCs. ${ }^{26}$ Furthermore, Nrf2 is activated by $5-\mathrm{FU}$, possibly as a result of drug-induced ROS production, in the human colon cancer HT-29 cell line. ${ }^{27}$ Consistent with this report, our results showed that ROS levels and Nrf2 and HO-1 expression were elevated in SNUC5/5-FUR cells. Induction of Nrf2-regulated cell defense genes is associated with increased resistance to 5 - FU, and is reversed by siNrf2. ${ }^{27}$ Furthermore, oncogene (K-Ras, B-Raf, or Myc)-induced Nrf2 transcription promotes ROS detoxification and carcinogenesis, and stably elevates the basal Nrf2 antioxidant program and thereby lowers levels of intracellular ROS. ${ }^{16}$ In the present study, SNUC5/5-FUR cells transfected with siRNA or shRNA against Nrf2 or HO-1 showed increased cytotoxicity and decreased cell proliferation in vitro and in vivo and were more sensitive to 5-FU treatment.
Cancer cells that adapt to oxidative stress by upregulating manganese superoxide dismutase, peroxiredoxin I, and $\mathrm{Bcl}-2$ are resistant to 5 -FU. ${ }^{28}$ Treatment with siRNA against ROS modulator 1 (Romo1) efficiently blocks 5-FU-induced ROS generation, indicating that 5-FU treatment stimulates ROS production through Romo1 induction. ${ }^{29}$ ROS may lead to epigenetic alterations that affect the genome and play a key role in human carcinogenesis. ${ }^{30}$ More specifically, ROS production is associated with alterations in DNA methylation patterns. ${ }^{31}$ In fact, many tumor suppressor genes are inactivated by ROS-mediated aberrant methylation of CpG island-rich promoter regions. ${ }^{32}$ For example, when exposed to oxidative stress, the tumor suppressor genes $\mathrm{p} 15^{\mathrm{INK} 4 \mathrm{~B}}$ and p $16^{\text {INK } 4 \mathrm{~A}}$ accrue aberrant methylation patterns, and their expression is ultimately silenced. ${ }^{33}$

DNA methylation is arguably the most intensively studied process in epigenetics with regard to carcinogenesis, and it has been the major focus of pharmacological interventions in clinical trials. This modification occurs predominantly at CG dinucleotide pairs and DNMTs transfer a methyl group to the 5-carbon position of the cytosine ring to form 5-mC. The conversion of $5-\mathrm{mC}$ into $5-\mathrm{hmC}, 5-\mathrm{fC}$, and 5-caC was processed by TET proteins. ${ }^{22,23,34}$ The genomic content of $5-\mathrm{hmC}, 5-\mathrm{fC}$, and 5 -caC can be increased or decreased through the overexpression or depletion of TET proteins. ${ }^{22}$ The 5-mC oxidative pathway mediated by the TET proteins may be relevant for the activation or repression of gene expression through its association with transcriptional repressors or activation factors. ${ }^{35}$

All TET proteins contain a cysteine-rich region, a doublestranded $\beta$-helix fold, and a CXXC domain, which is a DNA binding domain with $\mathrm{CpG}$-binding motif, and is involved in the recruitment of TET proteins to DNA. ${ }^{36}$ TET1 is the primary enzyme for oxidation of 5-mC to $5-\mathrm{fC}$, although the other TET proteins, TET2 and TET3, compensate for loss of TET1. ${ }^{37,38}$ In addition, it has been reported that TET1 plays an essential oncogenic role in leukemia. ${ }^{39}$ Therefore, the present study was focused on TET1 among the members of the TET family.

In the present study, the level of 5-mC was lower and the levels of 5-hmC and 5-fC were significantly higher in SNUC5/ 5 -FUR cells than in SNUC5 cells. The induction of TET1 leads to activation of Nrf2 in SNUC5/5-FUR cells. Our results also indicate that the increase in TET1 and TET process proteins by $5-\mathrm{FU}$ is mediated by its enhancement of ROS levels.

In conclusion, these results suggest that the development of resistance to $5-\mathrm{FU}$ in $\mathrm{CRC}$ cells involves changes in the expression of Nrf2 and $\mathrm{HO}-1$ that are induced by epigenetic modification of DNA demethylation. Therefore, Nrf2 might represent a potential therapeutic target to overcome the resistance of CRCs to 5-FU treatment.

\section{Materials and Methods}

Cell culture. The SNUC5 colon cancer cell line was obtained from the Korean Cell Line Bank (Seoul, Korea) and cultured at $37^{\circ} \mathrm{C}$ in a $5 \% \mathrm{CO}_{2}$ atmosphere in RPMI-1640 medium (Invitrogen, Grand Island, NY, USA) containing 10\% heatinactivated FBS (Sigma-Aldrich Co., St. Louis, MO, USA). The SNUC5/5-FUR cell line was obtained from the Research Center for Resistant Cells of Chosun University (Gwangju, Korea) and subcultured twice per week for more than 6 months until stable cell lines were established in $140 \mu \mathrm{M} 5$-FU. ${ }^{40}$

Cell proliferation assay. The effect of 5 -FU on cell proliferation was determined using the MTT assay. ${ }^{41}$ Cells were seeded in a 96-well plate at a 
a

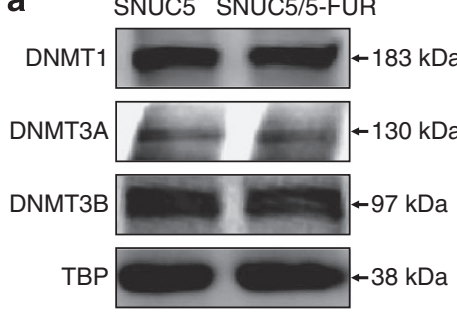

b

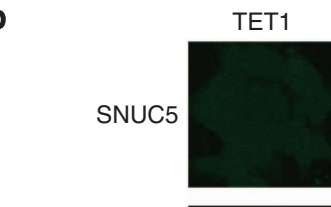

TET1
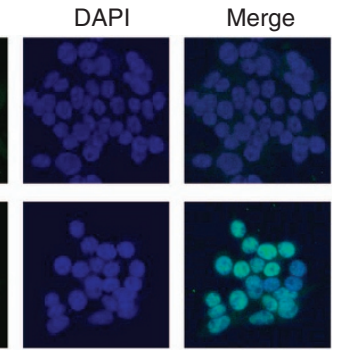

c
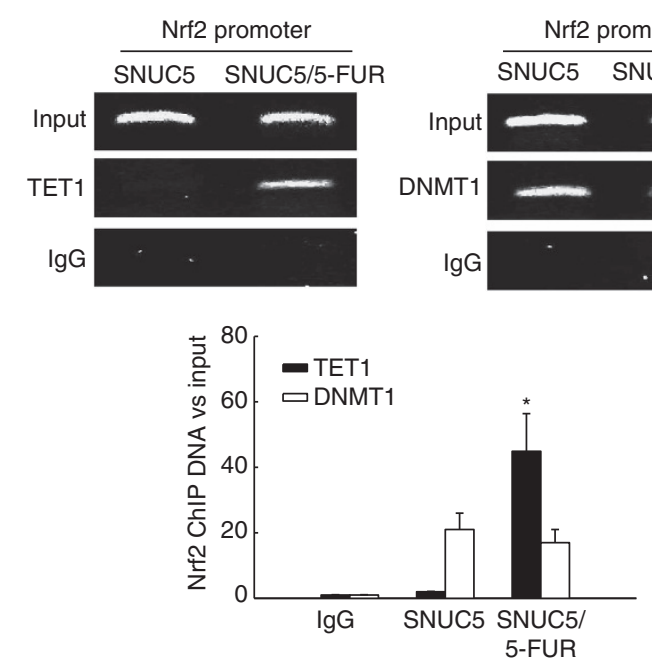

SNUC5 SNUC5/5-FUR

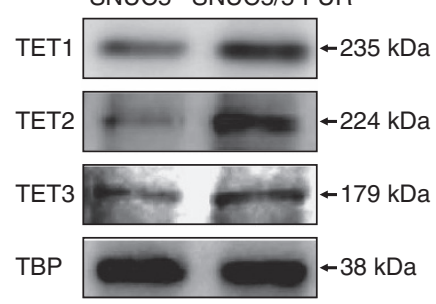

d

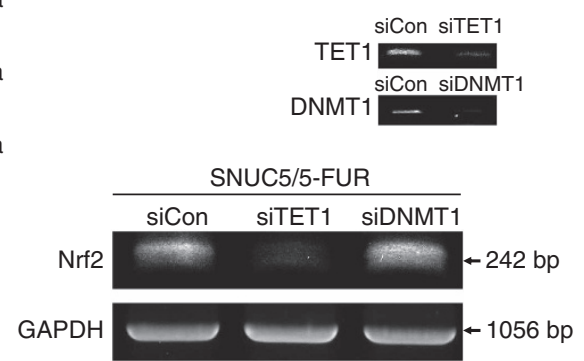

e
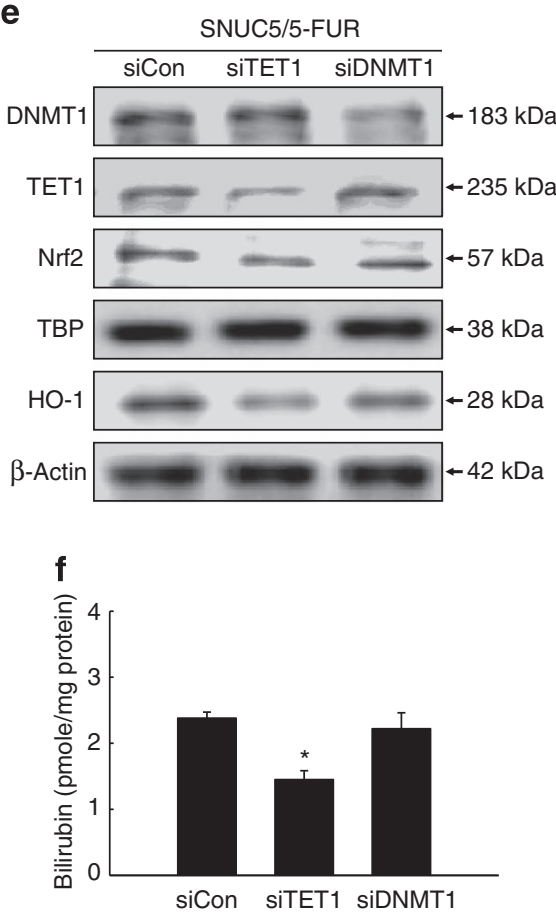

Figure 6 DNA methylation-related proteins in SNUC5 and SNUC5/5-FUR cells. (a) Expressions of DNA methylases DNMT1, DNMT3A, and DNMT3B, and DNA demethylases TET1, TET2, and TET3 were determined by western blotting. (b) Confocal images show TET1 (green), and DAPI staining indicates nuclei (blue). The merged image indicates the nuclear location of the TET1 protein. (c) ChIP analysis was performed using anti-TET1 or anti-DNMT1 antibodies and primers to amplify the Nrf2 promoter region. Bands indicate levels of TET1 or DNMT1 in the Nrf2 promoter region. Input represents amplification of total DNA from whole-cell lysates. *Significantly different from the level of TET1 in SNUC5 cells $(P<0.05)$. SNUC5/5-FUR cells were transfected with siCon, siTET1, or siDNMT1 RNA for $24 \mathrm{~h}$. (d) Nrf2 mRNA expression was evaluated by using RT-PCR. (e) Nrf2 and HO-1 protein expression were determined by using western blotting. (f) HO-1 activity was determined. *Significantly different from siCon-transfected cells $(P<0.05)$

density of $2 \times 10^{3}$ cells/well and treated with 5-FU. After incubating for $48 \mathrm{~h}, 50 \mu \mathrm{l}$ of the MTT stock solution $(2 \mathrm{mg} / \mathrm{ml})$ was added to each well to attain a total reaction volume of $250 \mu \mathrm{l}$. After $4 \mathrm{~h}$ of incubation, the supernatants were aspirated. The formazan crystals in each well were dissolved in $150 \mu \mathrm{l}$ dimethylsulfoxide and absorbance at $540 \mathrm{~nm}$ was read on a scanning multi-well spectrophotometer.

Colony formation analysis. Cells were seeded at a density of 500 cells per $60 \mathrm{~mm}$ dish and cultured for 10 days with either PBS as a control or with $9 \mu \mathrm{M}$ 5 -FU in SNUC5 cell and $2264 \mu \mathrm{M}$ 5-FU in SNUC5/5-FUR cells. During colony growth, the culture medium was replaced every 3 days. Colonies with more than 50 cells were counted under microscopic observation using a Diff-Quick staining kit (Sysmex, Kobe, Japan).

Detection of apoptosis. To identify apoptotic cells by using annexin $\mathrm{V}$ and PI staining method, cells were stained with $\mathrm{PI}$ and fluorescein isothiocyanate (FITC)-conjugated annexin V using the EzWay Annexin V-FITC apoptosis detection kit (Koma Biotech, Seoul, Korea). Briefly, cells were seeded on a 24-well plate at a density of $1.5 \times 10^{5}$ cells/well. At $16 \mathrm{~h}$ after plating, $9 \mu \mathrm{M} \mathrm{5}$-FU in SNUC5 cell or $2264 \mu \mathrm{M} 5$-FU in SNUC5/5-FUR cells was treated. After $24 \mathrm{~h}$, cells were washed twice in PBS, resuspended in $100 \mu \mathrm{l}$ of binding buffer supplemented with $5 \mu \mathrm{l}$ of annexin V-FITC and $5 \mu \mathrm{l}$ of PI solution, and incubated in the dark for $15 \mathrm{~min}$ at room temperature. After the addition of $450 \mu \mathrm{l}$ of binding buffer, the stained cells were kept on ice and subjected to analysis using a FACSCalibur flow cytometer (Becton Dickinson, Mountain View, CA, USA). FITC fluorescence was read at $515-545 \mathrm{~nm}$ and PI fluorescence was read at $564-606 \mathrm{~nm}$. To detect apoptotic cells by using TUNEL assay, it was performed with the in situ cell death detection kit (Roche Diagnostics, Indianapolis, IN, USA) according to the manufacturer's instructions. ${ }^{42}$ Briefly, cells were seeded on chamber slides at a density of $1.5 \times 10^{5}$ cells/well. At $16 \mathrm{~h}$ after plating, cells were treated with 9 or $2264 \mu \mathrm{M}$ 5-FU. After $24 \mathrm{~h}$, chamber slides were fixed with $4 \%$ paraformaldehyde for $1 \mathrm{~h}$ at $15-25^{\circ} \mathrm{C}$ and permeabilized in $0.1 \%$ sodium citrate containing $0.1 \%$ Triton X-100 for 2 min. After washing in PBS, sections were incubated with the TUNEL reaction mixture for $60 \mathrm{~min}$ at $37^{\circ} \mathrm{C}$. After washing with PBS, the stained cells were mounted onto a microscope slide in mounting medium (DAKO, 
a

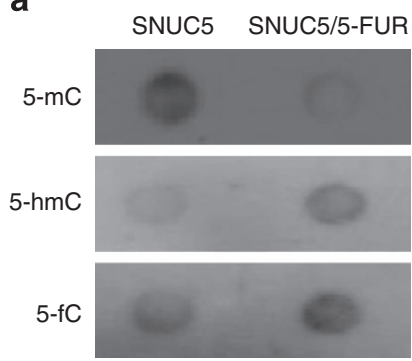

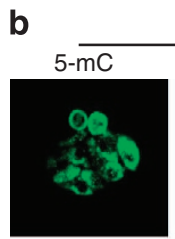

$5-\mathrm{hmC}$

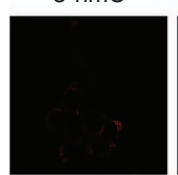

$5-\mathrm{fC}$
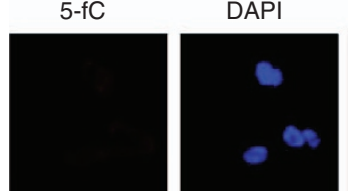

C

SNUC5

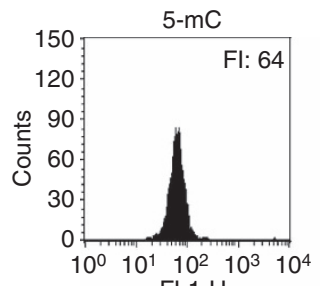

FL1-H

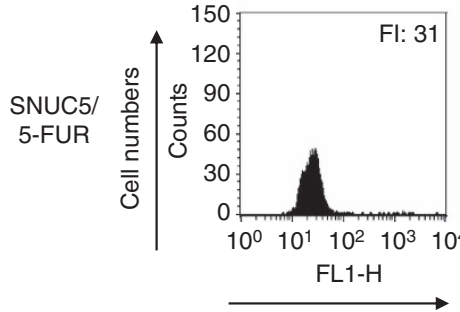

Fluorescence intensity

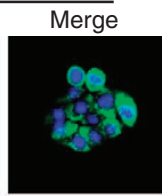

Merge

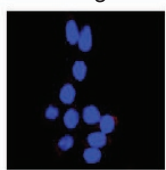

Merge

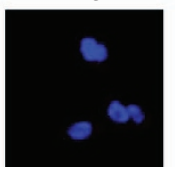

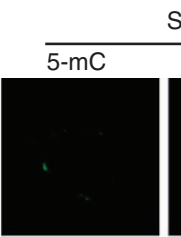

5-hmC

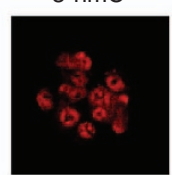

$5-f C$

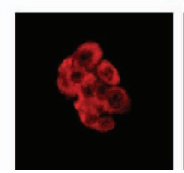

5-hmC
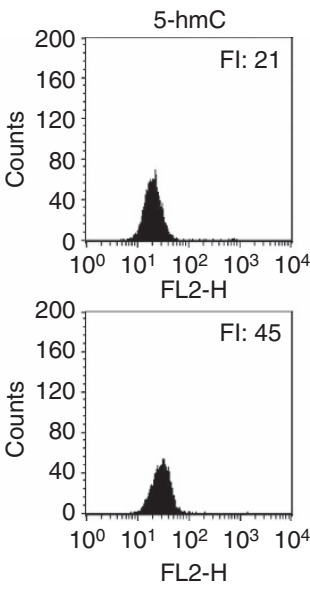

SNUC5/5-FUR

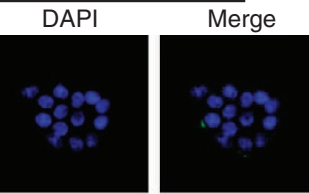

DAPI

Merge

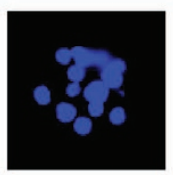

DAPI

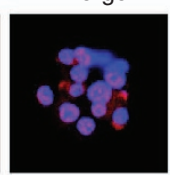

Merge
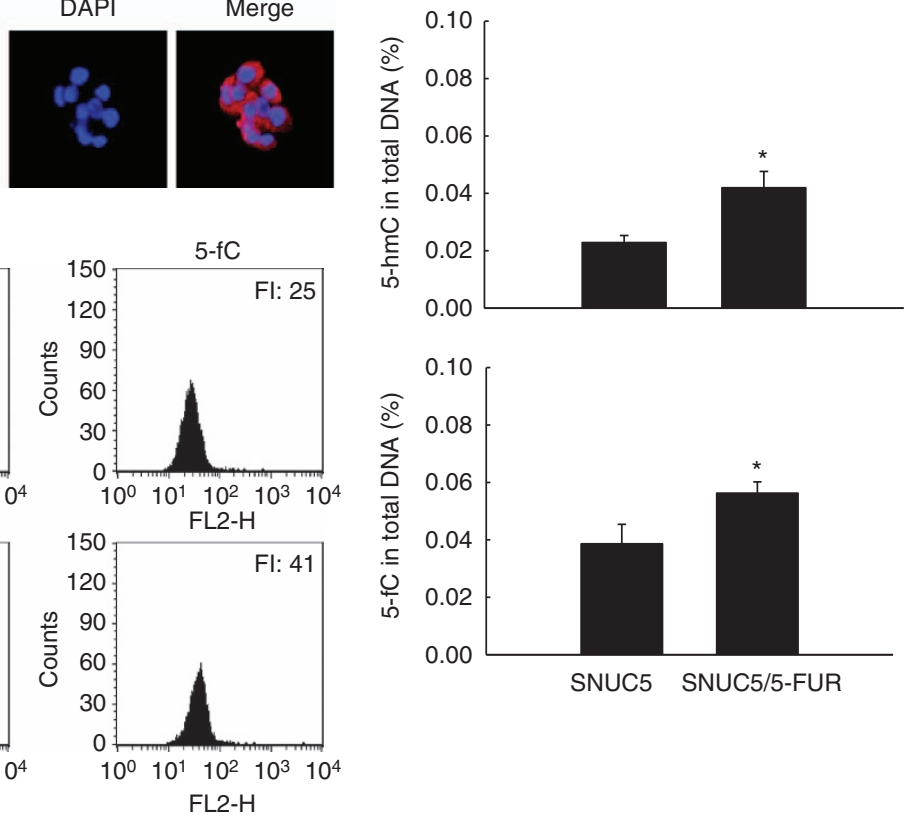

Figure 7 TET-catalyzed processes in SNUC5 and SNUC5/5-FUR cells. TET-catalyzed conversion of 5-mC to 5-hmc and 5-fC was assessed by (a) dot blot analysis, (b) confocal imaging, (c) flow cytometry, and (d) ELISA analysis. *Significantly different from the SNUC5 cells $(P<0.05)$

Carpinteria, CA, USA). Stained cells were observed under a fluorescence microscope (Olympus IX70, Olympus Optical Co., Japan).

Western blot analysis. Cells were harvested and to extract the total protein, cells were lysed in lysis buffer $(10 \mathrm{mM}$ Tris- $\mathrm{HCl}, \mathrm{pH} 7.9,150 \mathrm{mM} \mathrm{NaCl}, 1 \mathrm{mM}$ EDTA, $1 \mathrm{mM} \mathrm{NaF}, 0.1 \mathrm{mM}$ orthovanadate, $1 \% \mathrm{NP}-40,10 \mathrm{mg} / \mathrm{ml}$ leupeptin, $10 \mathrm{mg} / \mathrm{ml}$ aprotinin, and $0.1 \mathrm{mM}$ phenylmethylsulfonyl fluoride) and kept at $4^{\circ} \mathrm{C}$ for $30 \mathrm{~min}$. After centrifugation for $10 \mathrm{~min}$ at $10000 \times \mathrm{g}$, the supernatants measured the protein concentration and were stored at $-70^{\circ} \mathrm{C}$. In addition, to extract the nuclear protein, cells were harvested and then lysed on ice with $1 \mathrm{ml}$ of lysis buffer
(10 mM Tris- $\mathrm{HCl}, \mathrm{pH} 7.9,10 \mathrm{mM} \mathrm{NaCl}, 3 \mathrm{mM} \mathrm{MgCl}$, and $1 \% \mathrm{NP}-40$ ) for $4 \mathrm{~min}$. After $10 \mathrm{~min}$ of centrifugation at $3000 \times \mathrm{g}$, the pellets were resuspended in $50 \mu \mathrm{l}$ extraction buffer (20 mM HEPES, pH 7.9, 20\% glycerol, $1.5 \mathrm{mM} \mathrm{MgCl}_{2}, 0.2 \mathrm{mM}$ EDTA, $1 \mathrm{mM}$ DTT, and $1 \mathrm{mM}$ PMSF), incubated on ice for $30 \mathrm{~min}$, and centrifuged at $13000 \times g$ for $5 \mathrm{~min}$. The supernatant was then harvested as nuclear protein extracts and stored at $-70^{\circ} \mathrm{C}$ after determination of protein concentration. Aliquots of the lysates ( $40 \mu \mathrm{g}$ protein) were boiled for $5 \mathrm{~min}$ and electrophoresed on a $10 \%$ SDS-polyacrylamide gel. Proteins were transferred onto nitrocellulose membranes that were subsequently incubated with HO-1, Nrf2, TET1, TET2, TET3, DNMT3B, $\beta$-actin (Santa Cruz Biotechnology, Santa Cruz, CA, USA), 
DNMT1, phospho Nrf2, TATA box binding protein (TBP) antibodies (Abcam, Cambridge, MA, USA), and DNMT3A (Cell Signaling Technology, Beverly, MA, USA). The membranes were further incubated with secondary immunoglobulin-Ghorseradish peroxidase conjugates (Pierce, Rockford, IL, USA). TBP was used as loading control for nucleus protein and $\beta$-actin was used as loading control for total or cytosolic protein. Protein bands were detected using an enhanced chemiluminescence western blotting detection kit (Amersham, Little Chalfont, UK). The protein bands were visualized using a luminescent image analyzer.

HO-1 activity. HO-1 enzyme activity was measured as described previously. ${ }^{43}$ Briefly, cells were homogenized in $0.5 \mathrm{ml}$ of ice-cold $0.25 \mathrm{M}$ sucrose solution containing $50 \mathrm{mM}$ potassium phosphate buffer (pH 7.4). Homogenates were centrifuged at $200 \times g$ for $10 \mathrm{~min}$, and the supernatants were further centrifuged at $15000 \times \mathrm{g}$ for $60 \mathrm{~min}$. The pellet was resuspended in $50 \mathrm{mM}$ potassium phosphate buffer ( $\mathrm{pH}$ 7.4), and the amount of protein was determined. The reaction mixture $(200 \mu l)$ containing $0.2 \mathrm{mM}$ of the substrate hemin, $500 \mu \mathrm{g} / \mathrm{ml}$ cell lysate, $0.5 \mathrm{mg} / \mathrm{ml}$ rat liver cytosol as a source of biliverdin reductase, $0.2 \mathrm{mM} \mathrm{MgCl}$, $2 \mathrm{mM}$ glucose-6-phosphate, $1 \mathrm{U} / \mathrm{ml}$ glucose-6-phosphate dehydrogenase, $1 \mathrm{mM} \mathrm{NADPH}$, and $50 \mathrm{mM}$ potassium phosphate buffer ( $\mathrm{pH} 7.4$ ) was incubated at $37^{\circ} \mathrm{C}$ for $2 \mathrm{~h}$. The reaction was stopped by the addition of $0.6 \mathrm{ml}$ chloroform. After extraction, the chloroform layer was measured spectrophotometrically at $464 \mathrm{~nm}$. HO-1 activity was expressed as pmol of bilirubin per mg of protein.

Immunocytochemistry. Cells plated on chamber slides were fixed with $4 \%$ paraformaldehyde for $30 \mathrm{~min}$ and permeabilized with PBS containing $0.1 \%$ Triton $\mathrm{X}-100$ for $2.5 \mathrm{~min}$. Cells were treated with blocking medium (PBS containing $3 \%$ bovine serum albumin) for $1 \mathrm{~h}$ and incubated for $2 \mathrm{~h}$ with the primary antibody a

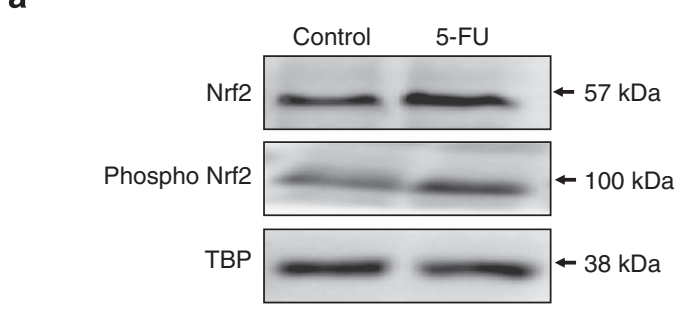

b

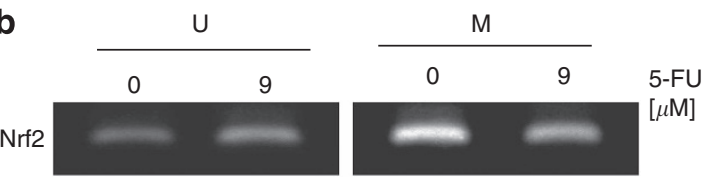

C

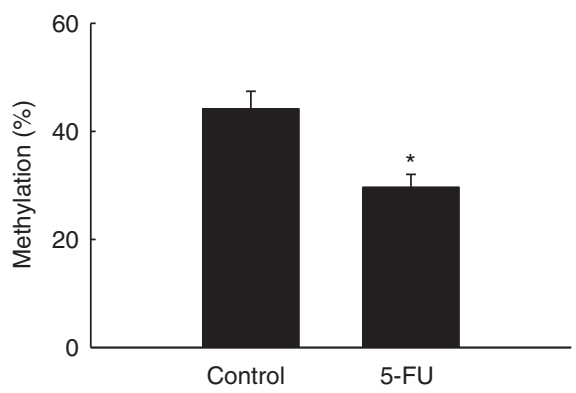

d

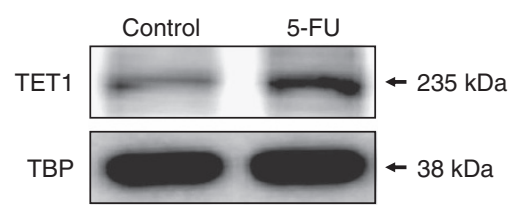

e

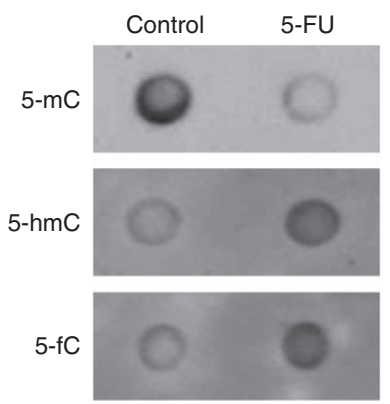

f
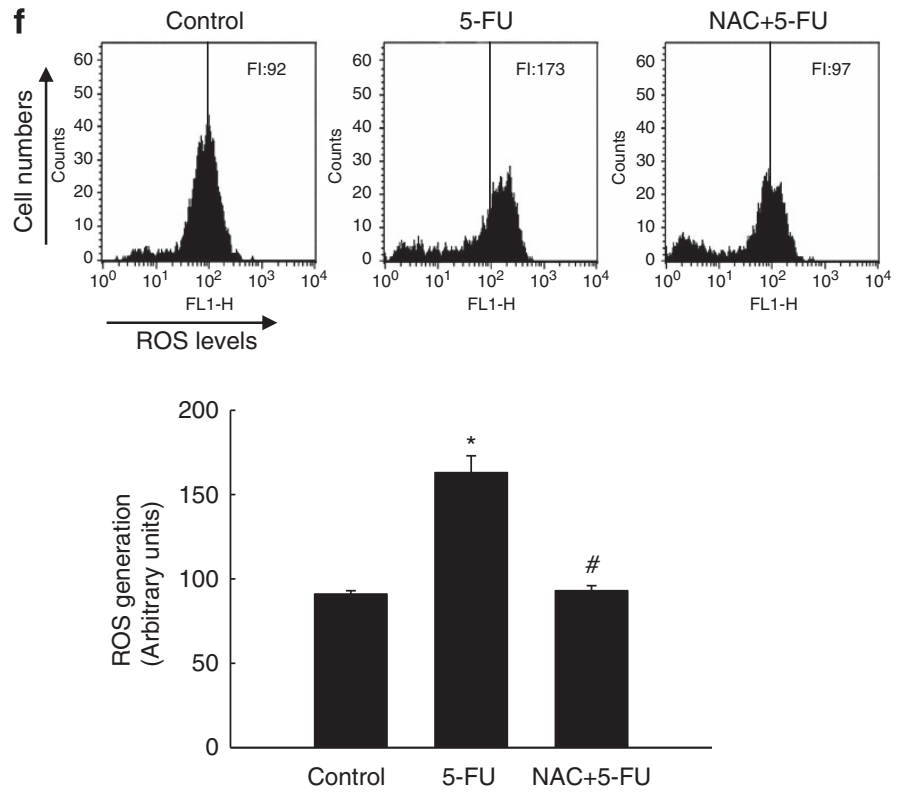

g

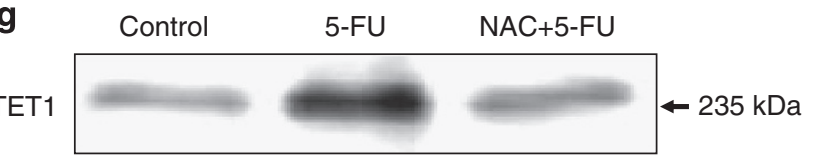

TBP

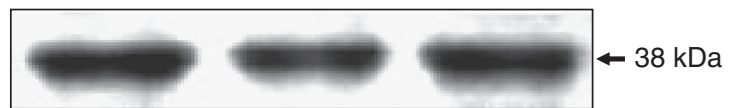

Figure 8 Effects of 5-FU-induced ROS on TET in SNUC5 cells. SNUC5 cells were treated with 5-FU $(9 \mu \mathrm{M})$ and then (a) Nrf2 expression was determined by western blotting. (b) Methylation of the Nrf2 promoter was performed on genomic DNA isolated from 5-FU-treated SNUC5 cells by using MS-PCR. M, methylated DNA; U, unmethylated DNA. (c) Real-time QMSP analysis of Nrf2 in 5-FU- treated SNUC5 cells was assessed. *Significantly different from control $(P<0.05)$. (d) TET1 expression was analyzed by western blotting and (e) TET-associated processes were analyzed by a dot blot assay. Cells were pretreated with $500 \mu \mathrm{M} \mathrm{NAC}$, incubated for $1 \mathrm{~h}$ at $37^{\circ} \mathrm{C}$, and treated with $9 \mu \mathrm{M} \mathrm{5-FU} \mathrm{for} 48 \mathrm{~h}$. Cells were then treated with $10 \mu \mathrm{M}$ DCF-DA for an additional 30 min at $37^{\circ} \mathrm{C}$. (f) Intracellular ROS levels were detected by flow cytometry. $\mathrm{Fl}$ indicates the fluorescence intensity of DCF. ${ }^{*}$ Significantly different from control $(P<0.05)$. "Significantly different from 5-FU-treated cells $(P<0.05)$. The expression of TET1 and its activity was detected by (g) western blotting, (h) a dot blot assay, and (i) flow cytometry 


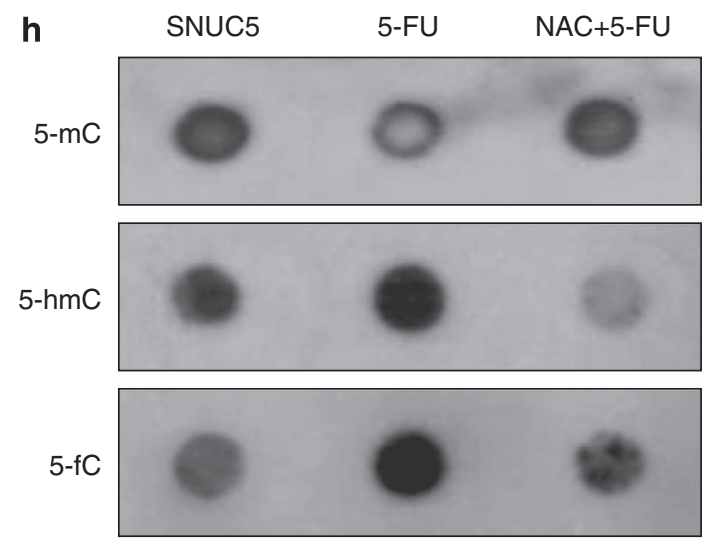

i
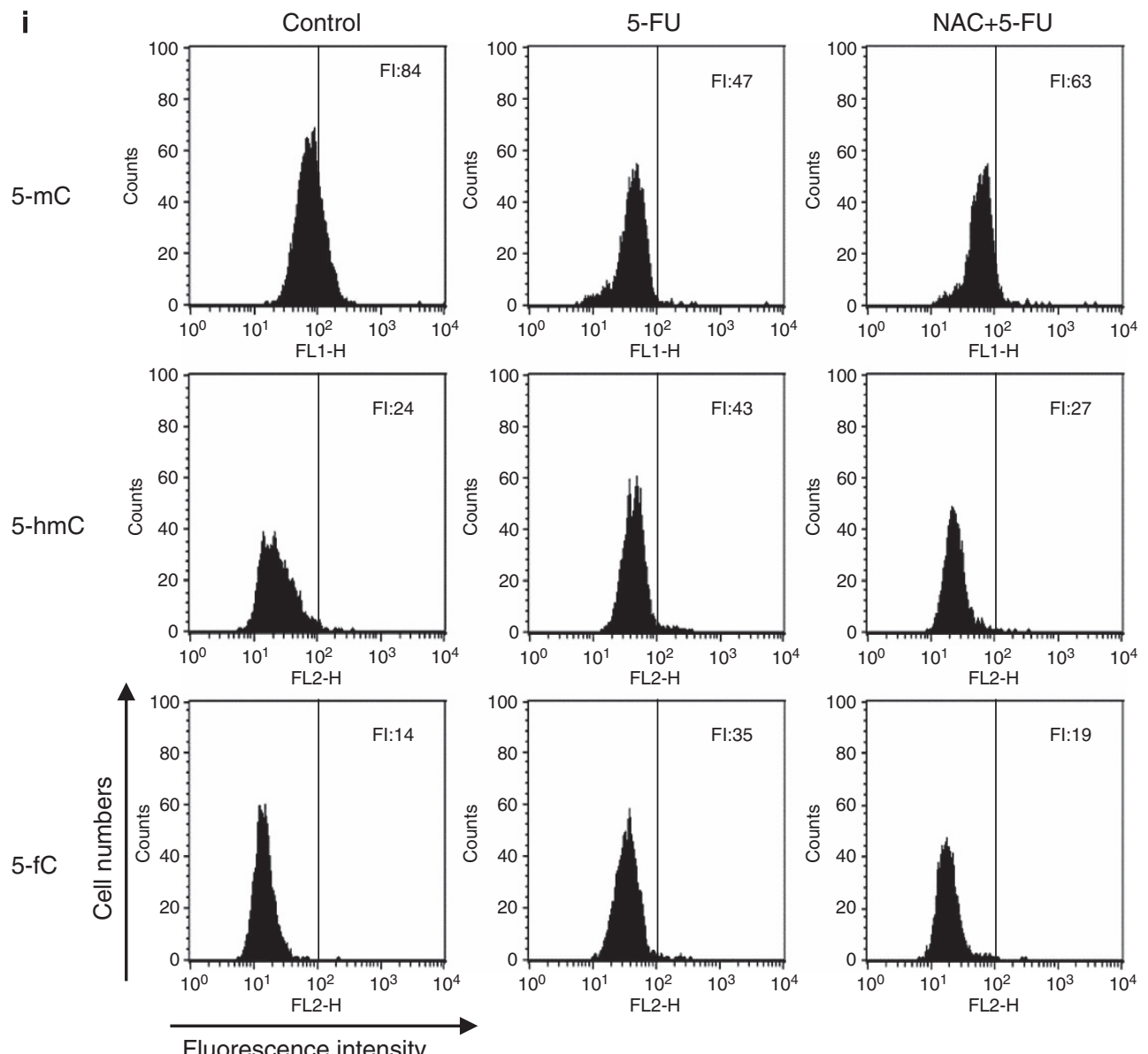

Figure 8 (Continued)

diluted in blocking medium. The primary antibody was detected using a FITCconjugated secondary antibody (1:500; Santa Cruz Biotechnology) for $1 \mathrm{~h}$. After washing with PBS, stained cells were mounted onto microscope slides in mounting medium containing DAPI (Vector, Burlingame, CA, USA) and imaged on a Zeiss confocal microscope using the LSM 510 program (Zeiss, Jena, Germany).

ChIP assay. The ChIP assay was performed using the simple ChIP enzymatic chromatin IP kit (Cell Signaling Technology) according to the manufacturer's protocol with slight modifications. Briefly, cells were crosslinked by addition of $1 \%$ formaldehyde. Chromatin was prepared and digested with nuclease for $12 \mathrm{~min}$ at $37^{\circ} \mathrm{C}$. ChIP was performed with an antibody against Nrf2 and IgG. Antibodies were added to the chromatin digests and incubated with constant rotation overnight at $4^{\circ} \mathrm{C}$. ChIP-grade protein $\mathrm{G}$ magnetic beads were then added to capture the immune complexes. The beads were washed and the immunoprecipitates were eluted with ChIP elution buffer. The crosslinks were reversed by incubation at $65^{\circ} \mathrm{C}$ for $30 \mathrm{~min}$. Proteinase $\mathrm{K}$ was added and samples were incubated at $65^{\circ} \mathrm{C}$ for $2 \mathrm{~h}$. The immunoprecipitated DNA fragments were purified using spin columns. DNA that was recovered from the immunoprecipitated complex was subjected to 35 cycles of PCR. The primers were as follows: sense, $5^{\prime}$-CCAGAAAGTGGGCATCAGCT-3' and antisense, $5^{\prime}$-GTCACATTTATGC TCGGCGG-3' for the HO-1 (Nrf2-binding site) gene promoter; and sense, $5^{\prime}$-TG AGATATTTTGCACATCCGATA- $3^{\prime}$ and antisense, $5^{\prime}$-ACTCTCAGGGTTCCTTTAC 
ACG-3' for the Nrf2 (DNMT1 and TET1-binding site) gene. The PCR products were separated on $2 \%$ agarose gels, and DNA bands were visualized using the Image program (NIH, Bethesda, MD, USA).

Detection of ROS. Cells were seeded in six-well plates at a density of $3 \times 10^{5}$ cells/well. Cells were treated with $25 \mu \mathrm{M}$ dichlorodihydrofluorescein diacetate (DCF-DA) and the fluorescence of $2^{\prime}, 7^{\prime}$-dichlorofluorescein (DCF) was detected using a flow cytometer (Becton Dickinson) and analyzed using CellQuest software. Image analysis for the generation of intracellular ROS was achieved by seeding cells on a coverslip-loaded six-well plate at a density of $2 \times 10^{5}$ cells/well. Then, $100 \mu \mathrm{M}$ DCF-DA was added to each well and cells were incubated for an additional $30 \mathrm{~min}$ at $37^{\circ} \mathrm{C}$. After washing with PBS, stained cells were mounted onto a microscope slide in mounting medium (DAKO). Images were acquired using the Laser Scanning Microscope 5 PASCAL program (Carl Zeiss) on a confocal microscope.

Transfection of siRNA and shRNA. For transfection of siRNA, cells were seeded at a density of $1.5 \times 10^{5}$ cells/well in 24-well plates and grown until $\sim 50 \%$ confluent. Cells were transfected with 10-50 nM siRNA against Nrf2, HO-1, TET1, and DNMT1 (Santa Cruz Biotechnology) by using Lipofectamine RNAiMax (Invitrogen, Carlsbad, CA, USA) based on the manufacturer's instructions. For transfection of shRNA, lentivirus vectors (Addgene, Cambridge, MA, USA) containing shNrf2 or shHO-1 were diluted in OptiMEM containing $6 \mu \mathrm{g} / \mathrm{ml}$ polybrene that was then added to SNUC5/5-FUR cells. After $72 \mathrm{~h}$, transfected cells were selected using puromycin $(5 \mu \mathrm{g} / \mathrm{ml})$ for $24 \mathrm{~h}$. Isolated individual cells were kept for up to 3 weeks, and silencing of $\mathrm{HO}-1$ and Nif2 was verified by measuring the protein level of HO-1 and Nrf2. The human shNrf2 sequence was $5^{\prime}-\mathrm{CCG}$ GCCGGCATTTCACTAAACACAACTCGAGTTGTGTTTAGTGAAATGCCGGTTTT T-3', the human HO-1 shRNA sequence was $5^{\prime}$-CCGGGCTGAGTTCATGAG GAACTTTCTCGAGAAAGTTCCTCATGAACTCAGCTTTTTG-3', and the shControl sequence was $5^{\prime}$-TTCTCCGAACGTGTCACGT-3'.

Tumorigenicity assay in nude mice. Nude mice ( $4-6$ weeks old) were used for xenograft studies. The scrambled shRNA (shCon)-, Nrf2-targeting shRNA (shNrf2)-, or HO-1-targeting shRNA (shHO-1)-transfected SNUC5/5-FUR cells $\left(3 \times 10^{6}\right.$ cells in Matrigel) were injected subcutaneously into the backs of nude mice. After 14 days, the period during which the tumors were established in mice implanted with shCon-transfected SNUC5/5-FUR cells, mice were treated with vehicle (PBS; $n=6)$ or 5 -FU $(20 \mathrm{mg} / \mathrm{kg} /$ day; $n=6)$ via direct injections into the tumor for every 2 days ( 9 times). The surface areas of tumors were measured with a vernier caliper at indicated days. The formula $(L / 2) \times(W / 2) \times \pi$ (where $L$ is the maximum diameter of each tumor, and $W$ is the length at right angles to $L$ ) was used to calculate the tumor surface area as previously described. ${ }^{44}$ Mice were killed and tumors were collected at 35 days after tumor cell injection.

Methylation-specific PCR. Bisulfate modification of DNA was performed using the Methylamp DNA modification kit (Epigentek, Pittsburgh, PA, USA) according to the manufacturer's instructions. To analyze methylation of Nrf2 DNA, MS-PCR was performed using an Epitect MSP kit (Qiagen, Valencia, CA, USA). $\mathrm{PCR}$ products were separated on $6 \%$ nondenaturing polyacrylamide gels, stained with ethidium bromide, and visualized under UV light. The Nrf2 promoter region was interrogated $1176 \mathrm{bp}$ upstream of the translation start site for potential $\mathrm{CpG}$ islands using the NCBI database. Two CpG-rich islands were identified within Nrf2 promoter region: -505 to -254 and -252 to +65 . PCR primers were designed to the promoter region spanning -479 to -342 , containing $11 \mathrm{CpG}$ sites, using methprimer program. The primer sets were as follows: for unmethylated forward, 5'-GGAGGTGTAGTTTTTATATTAATGT- $3^{\prime}$ and unmethylated reverse, 5'-ACCA ACTAAAATCCCAACAAACA-3'; for methylated forward, $5^{\prime}$-AGGGAGGCGT AGTTTTTATATTAAC-3' and methylated reverse, 5'-AACTAAAATCCCAA CAAACGAA- $3^{\prime}$.

Real-time quantitative MS-PCR (QMSP). Real-time QMPCR for Nrf2 was designed to the promoter region spanning -490 to -353 , containing 12 CpG sites, using methprimer program. The primer sets were as follows: for unmethylated forward, $5^{\prime}$-ACAAAAAACCTAAAAAAAATCTCCATT-3' and unmethylated reverse, 5'-GTTTTAAAGTGTTTGAATTTTAGTGA-3'; for methylated forward, 5-GAAAAACCTAAAAAAAATCTCCGTT-3' and methylated reverse, $5^{\prime}$-GTTTTAAAGCGTTCGAATTTTAGC- $3^{\prime}$. As a reference, the following primers specific to the unmethylated promoter region of the $\beta$-actin gene were used to yield a 133 bp amplicon: forward, 5'-TGGTGATGGAGGAGGTTTAGTAAGT-3' and reverse, $5^{\prime}$-AACCAATAAAACCTACTCCTCCCTTAA-3'. Calibration curves for target and reference genes were constructed using serial dilutions $(0.009-90 \mathrm{ng})$ of a commercially available fully methylated DNA (CpGenome Universal Methylated DNA, Serologicals Corp., Norcross, GA, USA). Amplification reactions were performed in triplicate in a total volume of $20 \mu$ l that contained $50 \mathrm{ng}$ of bisulphite-modified DNA, $600 \mathrm{nM}$ forward and reverse primers, and $10 \mu \mathrm{l}$ of QuantiTect $2 \times$ SYBR Green PCR mix (Invitrogen, Inc., Rockville, MD, USA). PCR conditions were as follows: $3 \mathrm{~min}$ at $95^{\circ} \mathrm{C}$ for initial denaturation, followed by 50 cycles of $15 \mathrm{~s}$ at $95^{\circ} \mathrm{C}$, and $1 \mathrm{~min}$ at $60-62^{\circ} \mathrm{C}$. PCR reactions were performed in 96-well plates in a 7900 sequence detector (Applied Biosystems, Carlsbad, CA, USA) and were analyzed using SDS 2.1.1 software (Applied Biosystems).

Reverse transcription-PCR (RT-PCR). Total RNA was isolated from cells using Trizol reagent (Gibco BRL, Grand Island, NY, USA). Complementary DNA (CDNA) was amplified in a reverse transcription reaction containing primers, dNTPs, and $0.5 \mathrm{U}$ of Taq DNA polymerase at a final volume of $25 \mu \mathrm{l}$. The PCR conditions were: $5 \mathrm{~min}$ at $94^{\circ} \mathrm{C}$ for initial denaturation, followed by 35 cycles of $1 \mathrm{~min}$ at $94^{\circ} \mathrm{C}, 1 \mathrm{~min}$ at $55^{\circ} \mathrm{C}$, and $1 \mathrm{~min}$ at $72^{\circ} \mathrm{C}$, and a final elongation period of $7 \mathrm{~min}$ at $72^{\circ} \mathrm{C}$. PCR amplification was carried out in a programmable thermal cycler (Perkin-Elmer Cetus 9600, Roche Molecular Systems Inc., Branchburg, NJ, USA). The primers used to amplify the Nrf2, TET1, and DNMT1 cDNAs were: Nrf2 sense, 5'-GAGAGCCCAGTCTTCATTGC-3', antisense, 5'-TTGGCTTCTG GACTTGGAAC-3'; TET1 sense, $5^{\prime}$-CCCGAATCAAGCGGAAGAATA-3', antisense, 5'-TACTTCAGGTTGCACGGT-3'; DNMT1 sense, 5'-CGCTGTATCTAGCA AGGGTCA-3', antisense, 5' ${ }^{\prime}$-TCGAATCTCGCGTAGTCTTG-3'; GAPDH sense, 5'-GTGGGCCGCCCTAGGCACCAGG-3', antisense 5'-GGAGGAAGAGGATGC GGCAGTG-3'. The amplified products were resolved on $1 \%$ agarose gel, stained with ethidium bromide, and photographed under ultraviolet light, using Image Quant TL analysis software (Amersham Bioscience, Uppsala, Sweden).

Measurement of 5-mC, 5-hmC, and 5-fC. For dot blot assay, DNA was isolated using a Puregene core kit A (Qiagen) and twofold serial dilutions of DNA were denatured by adding denaturing buffer $(0.5 \mathrm{M} \mathrm{NaOH}$ and $1.5 \mathrm{M} \mathrm{NaCl})$ and incubating at $65^{\circ} \mathrm{C}$ for $45 \mathrm{~min}$. After neutralization $(0.5 \mathrm{M}$ Tris- $\mathrm{HCl}$ and $1.5 \mathrm{M} \mathrm{NaCl})$, the solution was loaded in duplicate into a well placed on a positively charged nylon membrane (Amersham). The wells were then washed once with $2 \times$ saline sodium citrate buffer (SSC). The membrane was removed and briefly washed with $2 \times$ SCC and then UV crosslinked and dried. Membrane was blocked with $5 \%$ nonfat milk for $1 \mathrm{~h}$ and incubated with anti-5-mC, anti-5-hmC, and anti-5-fC (1:10000, Active Motif, Carlsbad, CA, USA) detected by HRP-conjugated secondary antibody and enhanced chemiluminescence. For image analysis, fixed cells were incubated for $2 \mathrm{~h}$ with anti-5-mC, anti-5-hmC, and anti-5-fC antibodies diluted in blocking medium (PBS containing $3 \%$ bovine serum albumin). The primary antibody was detected using a FITC-conjugated secondary antibody (1:500, Santa Cruz Biotechnology) for $1 \mathrm{~h}$. After washing with PBS, stained cells were mounted onto microscope slides in mounting medium containing DAPI (Vector) and imaged on a Zeiss confocal microscope using the LSM 510 program. For detection by using flow cytometry, cells were washed with PBS supplemented with $0.1 \%$ Tween- 20 and $1 \%$ bovine serum albumin (PBST-BSA), fixed with $0.25 \%$ paraformaldehyde at $37^{\circ} \mathrm{C}$ for $10 \mathrm{~min}$ and $88 \%$ methanol at $-20^{\circ} \mathrm{C}$ for at least 30 min. After two washes with PBST-BSA, the cells were treated with $2 \mathrm{~N} \mathrm{HCl}$ at $37^{\circ} \mathrm{C}$ for $30 \mathrm{~min}$ and were then neutralized with $0.1 \mathrm{~m}$ sodium borate $(\mathrm{pH} 8.5)$. The cells were blocked with $10 \%$ donkey serum in PBST-BSA for $20 \mathrm{~min}$ at $37^{\circ} \mathrm{C}$, incubated with anti-5-mC, anti-5-hmC, and anti-5-fC antibodies $(1 \mu \mathrm{g} / \mathrm{ml})$ for $45 \mathrm{~min}$ at $37^{\circ} \mathrm{C}$, followed by staining with secondary antibody conjugated with Rhodamine Red-X (Jackson ImmunoResearch Laboratories, Westgrove, PA, USA). The cells were washed with PBS three times and assessed by using a flow cytometer (Becton Dickinson). For quantification of 5-mC, 5-hmC, and 5-fC, the ELISA-based methylflash methylated DNA quantification kit, the methylflash hydroxymethylated DNA quantification kit, and methylflash 5-formylcytosine DNA quantification kit (Epigentek) were used. A total of $100 \mathrm{ng}$ of total DNA was used for 5 -mC quantification, $200 \mathrm{ng}$ for 5 -hmC quantification, and $300 \mathrm{ng}$ for 5 -fC quantification. The initial incubation time was $90 \mathrm{~min}$ and the final developing time was $10 \mathrm{~min}$. The absolute quantification of standard curves was generated by plotting the concentration of the positive control supplied with the assay against the optical density at $450 \mathrm{~nm}$ after performing the assay. The levels of 5-mC, 5-hmC, and 5-fC were assessed by absolute quantification. 
Statistical analysis. All measurements were performed in triplicate, and values are expressed as the mean \pm S.E.M. Results were analyzed using analysis of variance and Tukey's test to determine pairwise differences. $P<0.05$ was considered significant.

\section{Conflict of Interest}

The authors declare no conflict of interest

Acknowledgements. This study was supported by a grant from the National R\&D Program for Cancer Control, Ministry for Health and Welfare, Republic of Korea (1120340).

1. Longley DB, Harkin DP, Johnston PG. 5-fluorouracil: mechanisms of action and clinica strategies. Nat Rev Cancer 2003; 3: 330-338.

2. Was H, Dulak J, Jozkowicz A. Heme oxygenase-1 in tumor biology and therapy. Curr Drug Targets 2010; 11: 1551-1570.

3. Tanaka S, Akaike T, Fang J, Beppu T, Ogawa M, Tamura F et al. Antiapoptotic effect of haem oxygenase-l induced by nitric oxide in experimental solid tumour. Brit J Cancer2003; 88: 902-909.

4. Becker JC, Fukui H, Imai Y, Sekikawa A, Kimura T, Yamagishi H et al. Colonic expression of heme oxygenase-1 is associated with a better long-term survival in patients with colorectal cancer. Scand J Gastroenterol 2007; 42: 852-858.

5. Kang KA, Maeng YH, Zhang R, Yang YR, Piao MJ, Kim KC et al. Involvement of heme oxygenase-1 in Korean colon cancer. Tumour Biol 2012; 33: 1031-1038.

6. Jozkowicz A, Was H, Dulak J. Heme oxygenase-1 in tumors: is it a false friend? Antioxid Redox Signal 2007; 9: 2099-2117.

7. Tsai JR, Wang HM, Liu PL, Chen YH, Yang MC, Chou SH et al. High expression of heme oxygenase- 1 is associated with tumor invasiveness and poor clinical outcome in non-smal cell lung cancer patients. Cell Oncol 2012; 35: 461--471.

8. Na HK, Surh YJ. Oncogenic potential of Nrf2 and its principal target protein heme oxygenase-1. Free Radic Biol Med 2013; 67: 353-365

9. Berberat PO, Dambrauskas Z, Gulbinas A, Giese T, Giese N, Künzli B et al. Inhibition of heme oxygenase- 1 increases responsiveness of pancreatic cancer cells to anticancer treatment. Clin Cancer Res 2005; 11: 3790-3798.

10. Wang W, McLeod H, Cassidy J, Collie-Duguid ES. Mechanisms of acquired chemoresistance to 5 -fluorouracil and tomudex: thymidylate synthase dependent and independent networks. Cancer Chemother Pharmacol 2007; 59: 839-845.

11. Kim SK, Yang JW, Kim MR, Roh SH, Kim HG, Lee KY et al. Increased expression of Nrf2/ ARE-dependent anti-oxidant proteins in tamoxifen-resistant breast cancer cells. Free Radic Biol Med 2008; 45: 537-546.

12. Zhang DD, Hannink M. Distinct cysteine residues in Keap1 are required for Keap1dependent ubiquitination of $\mathrm{Nrf2}$ and for stabilization of $\mathrm{Nrf2}$ by chemopreventive agents and oxidative stress. Mol Cell Biol 2003; 23: 8137-8151.

13. Zhang DD. Mechanistic studies of the Nrf2-Keap1 signaling pathway. Drug Metab Rev 2006; 38: 769-789.

14. Kwak MK, Wakabayashi N, Itoh K, Motohashi H, Yamamoto M, Kensler TW. Modulation of gene expression by cancer chemopreventive dithiolethiones through the Keap1-Nrf2 pathway - identification of novel gene clusters for cell survival. J Biol Chem 2003; 278: $8135-8145$.

15. Lee JM, Calkins MJ, Chan KM, Kan YW, Johnson JA. Identification of the NF-E2-related factor-2-dependent genes conferring protection against oxidative stress in primary cortical astrocytes using oligonucleotide microarray analysis. J Biol Chem 2003; 278: 12029-12038.

16. DeNicola GM, Karreth FA, Humpton TJ, Gopinathan A, Wei C, Frese K et al. Oncogeneinduced Nrf2 transcription promotes ROS detoxification and tumorigenesis. Nature 2011 475: 106-109.

17. Sporn MB, Liby KT. NRF2 and cancer: the good, the bad and the importance of context. Nat Rev Cancer 2012; 12: 564-571.

18. Kastl L, Brown I, Schofield AC. Altered DNA methylation is associated with docetaxe resistance in human breast cancer cells. Int J Oncol 2010; 36: 1235-1241.

19. Kwon OH, Park JL, Baek SJ, Noh SM, Song KS, Kim SY et al. Aberrant upregulation of ASCL2 by promoter demethylation promotes the growth and resistance to 5 -fluorouracil of gastric cancer cells. Cancer Sci 2013; 104: 391-397.

20. Phuong NT, Kim SK, Lim SC, Kim HS, Kim TH, Lee KY et al. Role of PTEN promoter methylation in tamoxifen-resistant breast cancer cells. Breast Cancer Res Treat 2011; 130 73-83.

21. Segura-Pacheco B, Perez-Cardenas E, Taja-Chayeb L, Chavez-Blanco A Revilla-Vazquez A, Benitez-Bribiesca $L$ et al. Global DNA hypermethylation-associated cancer chemotherapy resistance and its reversion with the demethylating agent hydralazine. J Transl Med 2006; 4: 32

22. Ito S, Shen L, Dai Q, Wu SC, Collins LB, Swenberg JA et al. Tet proteins can convert 5-methylcytosine to 5-formylcytosine and 5-carboxylcytosine. Science 2011; 333: 1300-1303.
23. Ito S, D'Alessio AC, Taranova OV, Hong K, Sowers LC, Zhang Y. Role of Tet proteins in $5 \mathrm{mc}$ to $5 \mathrm{hmc}$ conversion, Es-cell self-renewal and inner cell mass specification. Nature 2010; 466: 1129-1133.

24. Crea F, Nobili S, Paolicchi E, Perrone G, Napoli C, Landini I et al. Epigenetics and chemoresistance in colorectal cancer: an opportunity for treatment tailoring and nove therapeutic strategies. Drug Resist Updat 2011; 14: 280-296.

25. Arnold CN, Goel A, Boland CR. Role of hMLH1 promoter hypermethylation in drug resistance to 5-fluorouracil in colorectal cancer cell lines. Int J Cancer 2003; 106: 66-73.

26. Arlt A, Bauer I, Schafmayer C, Tepel J, Müerköster SS, Brosch M et al. Increased proteasome subunit protein expression and proteasome activity in colon cancer relate to an enhanced activation of nuclear factor E2-related factor 2 (Nrf2). Oncogene 2009; 28: 3983-3996.

27. Akhdar H, Loyer P, Rauch C, Corlu A, Guillouzo A, Morel F. Involvement of Nrf2 activation in resistance to 5-fluorouracil in human colon cancer HT-29 cells. Eur J Cancer 2009; 45 : 2219-2227.

28. Zhang P, Liu B, Kang SW, Seo MS, Rhee SG, Obeid LM. Thioredoxin peroxidase is a novel inhibitor of apoptosis with a mechanism distinct from that of Bcl-2. J Biol Chem 1997; 272: 30615-30618.

29. Hwang IT, Chung YM, Kim JJ, Chung JS, Kim BS, Kim HJ et al. Drug resistance to 5-FU linked to reactive oxygen species modulator 1. Biochem Biophys Res Commun 2007; 359: 304-310.

30. Ziech D, Franco R, Pappa A, Panayiotidis MI. Reactive oxygen species (ROS)induced genetic and epigenetic alterations in human carcinogenesis. Mutat Res 2011; 711: 167-173.

31. Donkena KV, Young CY, Tindall DJ. Oxidative stress and DNA methylation in prostate cancer. Obstet Gynecol Int 2010; 2010: 302051.

32. Ushijima T, Takada EO. Aberrant methylations in cancer cells: where do they come from? Cancer Sci 2005; 96: 206-211.

33. Toyokuni A. Molecular mechanisms of oxidative stress-induced carcinogenesis: from epidemiology to oxygenomics. IUMBM Life 2008; 60: 441-447.

34. Wu H, Zhang Y. Mechanisms and functions of Tet protein-mediated 5-methylcytosine oxidation. Genes Dev 2011; 25: 2436-2452.

35. Iyer LM, Tahiliani M, Rao A, Aravind L. Prediction of novel families of enzymes involved in oxidative and other complex modifications of bases in nucleic acids. Cell Cycle 2009; 8 : 1698-1710.

36. Szwagierczak A, Bultmann S, Schmidt CS, Spada F, Leonhardt H. Sensitive enzymatic quantification of 5-hydroxymethylcytosine in genomic DNA. Nucleic Acids Res 2010; 38 : e181

37. Dawlaty MM, Ganz K, Powell BE, Hu YC, Markoulaki S, Cheng AW et al. Tet1 is dispensable for maintaining pluripotency and its loss is compatible with embryonic and postnatal development. Cell Stem Cell 2011; 9: 166-175.

38. Rudenko A, Dawlaty MM, Seo J, Cheng AW, Meng J, Le T et al. Tet1 is critical for neuronal activity-regulated gene expression and memory extinction. Neuron 2013; 79: 1109-1122.

39. Huang $\mathrm{H}$, Jiang X, Li Z, Li Y, Song CX, He C et al. TET1 plays an essential oncogenic role in MLL-rearranged leukemia. Proc Natl Acad Sci USA 2013; 110: 11994-11999.

40. Jung GR, Kim KJ, Choi CH, Lee TB, Han SI, Han HK et al. Effect of betulinic acid on anticancer drug-resistant colon cancer cells. Basic Clin Pharmacol Toxicol 2007; 101 $277-285$

41. Carmichael J, DeGraff WG, Gazdar AF, Minna JD, Mtchell JB. Evaluation of a tetrazoliumbased semiautomated colorimetric assay: assessment of chemosensitivity testing. Cancer Res 1987; 47: 936-942.

42. Zheng JN, Sun YF, Pei DS, Liu JJ, Chen JC, Li W et al. Inhibition of proliferation and induction of apoptosis in human renal carcinoma cells by anti-telomerase small interfering RNAs. Acta Biochim Biophys Sin (Shanghai) 2006; 38: 500-506.

43. Alaoui-Jamali MA, Bismar TA, Gupta A, Szarek WA, Su J, Song W et al. A nove experimental heme oxygenase-1-targeted therapy for hormone-refractory prostate cancer. Cancer Res 2009; 69: 8017-8024.

44. Xiong SD, Yu K, Liu XH, Yin LH, Kirschenbaum A, Yao S et al. Ribosome-inactivating proteins isolated from dietary bitter melon induce apoptosis and inhibit histone deacetylase- 1 selectively in premalignant and malignant prostate cancer cells. Int $J$ Cancer 2009; 125: 774-782.

(2) (i) () Cell Death and Disease is an open-access journal published by Nature Publishing Group. This work is licensed under a Creative Commons Attribution-NonCommercialNoDerivs 3.0 Unported License. The images or other third party material in this article are included in the article's Creative Commons license, unless indicated otherwise in the credit line; if the material is not included under the Creative Commons license, users will need to obtain permission from the license holder to reproduce the material. To view a copy of this license, visit http://creativecommons.org/licenses/ by-nc-nd/3.0/ 